\title{
Retrieval of water vapor vertical distributions in the upper troposphere and the lower stratosphere from SCIAMACHY limb measurements
}

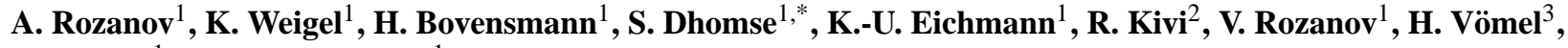 \\ M. Weber ${ }^{1}$, and J. P. Burrows ${ }^{1}$ \\ ${ }^{1}$ Institute of Environmental Physics (IUP), University of Bremen, Bremen, Germany \\ ${ }^{2}$ Finnish Meteorological Institute, Helsinki, Finland \\ ${ }^{3}$ Meteorological Observatory Lindenberg, Deutscher Wetterdienst, Lindenberg, Germany \\ * now at: School of Earth and Environment, University of Leeds, Leeds, UK
}

Received: 25 August 2010 - Published in Atmos. Meas. Tech. Discuss.: 8 September 2010

Revised: 27 April 2011 - Accepted: 9 May 2011 - Published: 23 May 2011

\begin{abstract}
This study describes the retrieval of water vapor vertical distributions in the upper troposphere and lower stratosphere (UTLS) altitude range from space-borne observations of the scattered solar light made in limb viewing geometry. First results using measurements from SCIAMACHY (Scanning Imaging Absorption spectroMeter for Atmospheric CHartographY) aboard ENVISAT (Environmental Satellite) are presented here. In previous publications, the retrieval of water vapor vertical distributions has been achieved exploiting either the emitted radiance leaving the atmosphere or the transmitted solar radiation. In this study, the scattered solar radiation is used as a new source of information on the water vapor content in the UTLS region. A recently developed retrieval algorithm utilizes the differential absorption structure of the water vapor in $1353-1410 \mathrm{~nm}$ spectral range and yields the water vapor content in the 11$25 \mathrm{~km}$ altitude range. In this study, the retrieval algorithm is successfully applied to SCIAMACHY limb measurements and the resulting water vapor profiles are compared to in situ balloon-borne observations. The results from both satellite and balloon-borne instruments are found to agree typically within $10 \%$.
\end{abstract}

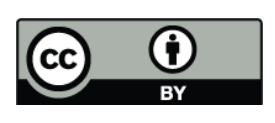

Correspondence to: A. Rozanov (alexei.rozanov@iup.physik.unibremen.de)

\section{Introduction}

A need for a good knowledge of stratospheric and upper tropospheric water vapor contents is well justified due to its major role in determining the radiative and chemical properties of the Earth's atmosphere. Water vapor is one of the major and natural greenhouse gases and an important part of the hydrological cycle. Model studies show that also stratospheric water vapor plays an important role in the Earth's radiative budget affecting the climate (de F. Forster and Shine, 1999; Solomon et al., 2010). Furthermore, it contributes to stratospheric cooling and is responsible for ozone destruction by providing odd hydrogen and participating in the formation of PSCs, see e.g. Stenke and Grewe (2005). Especially in the upper troposphere and lower stratosphere (UTLS) region, water vapor can be used as a tracer to study atmospheric dynamics and stratosphere-troposphere exchange processes (Pan et al., 2007). In the tropical lowermost stratosphere, observed water vapor changes are indicators for changes in the tropical upwelling, relevant for stratospheric entry of many trace species, and long-term changes in the stratospheric circulation (Randel et al., 2006; Dhomse et al., 2008).

Information on water vapor is commonly obtained by passive remote sensing in the infrared or microwave spectral ranges or from in situ measurements. Passive remote sensing technique finds the widest application in space-borne observations. A variety of satellite instruments used to detect water vapor and their measurement principles are briefly discussed below. Besides the space-borne observations, passive remote sensing is also used for water vapor measurements

Published by Copernicus Publications on behalf of the European Geosciences Union. 
by balloon, aircraft, and ground-based instruments (FriedlVallon et al., 2004; Vasic et al., 2005; Deuber et al., 2004; Nedoluha et al., 1995). In situ observations are usually performed from balloon or aircraft using FISH (Zöger et al., 1999) or FLASH (Sitnikov et al., 2007) sensors or frost point hygrometers (Vömel et al., 2007b). Furthermore, water vapor can be measured by active remote sensing with lidars (Argall et al., 2007; Kiemle et al., 2008).

Balloon and ground-based soundings are commonly used to determine 1-D distributions of water vapor on a continuous time basis and thus are very interesting for local trend analyses. From aircraft a two-dimensional section of the water vapor distribution in the atmosphere along the flight track is obtained. Space-borne observations provide the only source of a long-term global information.

In the last decades several satellite instruments capable to measure vertical distributions of the water vapor have been put in operation. Most of these instruments either measure the direct solar light transmitted through the Earth's atmosphere in solar occultation mode or collect the radiance emitted by the atmospheric species in limb or nadir viewing geometry. Measurements of water vapor distributions in solar occultation geometry are currently being performed by ACEFTS (Boone et al., 2005) and ACE-MAESTRO (Sioris et al., 2010b) instruments onboard SCISAT and SCIAMACHY onboard ENVISAT. Earlier this technique was exploited by HALOE (Harries et al., 1996), SAGE II (Thomason et al., 2004), SAGE III (Thomason et al., 2010), POAM III (Boone et al., 2005), and ILAS II (Nakajima et al., 2006) instruments. Measurements of the radiance emitted by the Earth's atmosphere, are performed by Microwave Limb Sounder onboard the Aura satellite (Read et al., 2007), SMR onboard Odin (Urban et al., 2007), and MIPAS onboard ENVISAT (Milz et al., 2005) in the limb viewing geometry. Previously this kind of measurements was done by Microwave Limb Sounder onboard UARS (Harwood et al., 1993) and JEM/SMILES on the International Space Station (Kikuchi et al., 2010). Nadir-viewing instruments observing the emitted radiation in the infrared spectral range are AIRS onboard the Aqua satellite (Hagan et al., 2004) and IASI onboard MetOp (Pougatchev et al., 2009). SCIAMACHY (Burrows et al., 1995) is the first space-borne instrument providing vertical distributions of the water vapor from observations of the scattered solar light performed in limb viewing geometry. As discussed below, SCIAMACHY retrievals have maximum sensitivity in UTLS altitude range and provide, thus, a new and complementary source of information on UTLS water vapor which has never been used before.

In this study, we provide a short description of key aspects of SCIAMACHY limb observations and describe in detail the new retrieval approach. In addition, we analyze the sensitivity of retrievals and influence of key atmospheric parameters upon the retrieved water vapor profiles. Finally, we perform a first verification of the retrieved vertical profiles by comparing with measurements made by balloon-borne in situ sen- sors. The retrieval implementation and parameter settings described in this study refer to the version 3.0 of the IUP Bremen water vapor retrieval algorithm.

\section{SCIAMACHY limb observations}

The Scanning Imaging Absorption spectroMeter for Atmospheric CHartographY (SCIAMACHY) (Burrows et al., 1995; Bovensmann et al., 1999), is a national contribution to the payload on the European Environmental Satellite (ENVISAT) launched on 1 March 2002. It is a part of a newgeneration of space-borne instruments making spectrally resolved measurements in several different viewing modes: alternate nadir and limb observations of the solar radiation scattered in the atmosphere or reflected by the Earth's surface as well as observations of the light transmitted through the atmosphere during the solar and when feasible lunar occultations. The SCIAMACHY instrument is a passive imaging spectrometer comprising 8 spectral channels covering a wide spectral range from 214 to $2380 \mathrm{~nm}$. Each spectral channel comprises a grating spectrometer equipped with a 1024 element diode array as a detector. For the current study, only measurements in the spectral channel $6(1050-1700 \mathrm{~nm})$ are used. The spectral resolution is about $1.5 \mathrm{~nm}$ and the spectral sampling is about $0.75 \mathrm{~nm}$.

In the limb viewing geometry, the SCIAMACHY instrument observes the atmosphere tangentially to the Earth's surface starting at about $3 \mathrm{~km}$ below the horizon, i.e., when the Earth's surface is still within the field of view of the instrument, and then scanning vertically up to the top of the atmosphere (about $100 \mathrm{~km}$ tangent height). At each tangent height a horizontal scan lasting $1.5 \mathrm{~s}$ is performed followed by an elevation step of about $3.3 \mathrm{~km}$. No measurements are performed during the vertical step. Thus, a limb observation sequence is performed with a vertical sampling of $3.3 \mathrm{~km}$. In the altitude range relevant for this study, most typical tangent heights of limb measurements are located around 12.0, 15.3, $18.9,21.9$, and $25.2 \mathrm{~km}$. The vertical instantaneous field of view of the SCIAMACHY instrument is about $2.6 \mathrm{~km}$ at the tangent point. Although the horizontal instantaneous field of view of the instrument is about $110 \mathrm{~km}$ at the tangent point, the horizontal cross-track resolution is mainly determined by the integration time during the horizontal scan reaching typically about $240 \mathrm{~km}$. For a typical limb measurement, the observed signal integrated by the instrument is readout four times per horizontal scan that results in four independent limb radiance profiles obtained during a vertical scan. These four radiance profiles are often referred to as the azimuthal measurements. The entire distance at the tangent point covered by the horizontal scan is about $960 \mathrm{~km}$. The horizontal along-track resolution is estimated to be about $400 \mathrm{~km}$.

The signal to noise ratio of SCIAMACHY limb spectra decreases with increasing tangent height ranging from 400 to 700 near $1400 \mathrm{~nm}$ in the UTLS altitude region. Details 
about signal to noise characteristics of the SCIAMACHY instrument can be found in Noël et al. (1998).

Throughout this study, version 6.03 of SCIAMACHY Level 1 data is used with the calibration steps from 0 to 5 applied in the extractor software, i.e., the wavelength calibration is performed and the corrections for memory effect, leakage current, pixel-to-pixel gain, etalon, and internal straylight are accounted for. The polarization correction as well as the absolute radiometric calibration are skipped.

\section{Retrieval approach}

\subsection{Selection of the spectral window}

In the spectral range considered in this study, scattered solar light detected by a limb viewing satellite instrument exhibits a significant contribution of the multiple scattering. Thus, an observed signal is affected by amounts of atmospheric species not only in altitude layers intersected by the instrument line of sight but also in layers far below the tangent point. As a result of an increasing optical depth of the observed air mass and frequency of clouds in the lower atmosphere, the light collected by the instrument at lower tangent heights (below about $\sim 10 \mathrm{~km}$ ) typically originates from upper altitudes rather than from the tangent point area. Thus, atmospheric species in the lower atmosphere can not be retrieved in a usual way. Influence of lower atmospheric abundances upon measurements at upper tangent heights is almost negligible when observing atmospheric species with maximum number densities in the stratosphere and relatively small amounts in the lower atmosphere, such as, for example, $\mathrm{O}_{3}, \mathrm{NO}_{2}$, and $\mathrm{BrO}$. However, this issue becomes problematic for species as water vapor exhibiting low abundances in the stratosphere and very high number densities in the lower atmosphere. For these species, the signal from the lower troposphere can dominate even in stratospheric observations.

In this study, contribution of the lower tropospheric water vapor in the limb signal observed at upper tangent heights is suppressed by selecting a spectral range within a strong water vapor absorption band. As a result of a strong absorption, effective path lengths of photons in the lower troposphere become shorter and the number of photons being multiply scattered within the troposphere and then entering the instrument field of view is decreased compared to weaker bands. This is illustrated in Fig. 1. The upper panel shows simulated limb radiance in spectral channels 4 , 5 , and 6 of SCIAMACHY at a tangent height of $12 \mathrm{~km}$. The spectral channels are separated by gaps. The simulations are done with the SCIATRAN radiative transfer model (Rozanov et al., 2005; Rozanov, 2011) assuming a vertical distribution of the water vapor according to the US Standard 1976 model atmosphere (Committee on Extension to the Standard Atmosphere, 1976). The incident solar flux is assumed to be equal $\pi \mathrm{W} \mathrm{m}^{-2} \mu \mathrm{m}^{-1}$. In the lower panel of Fig. 1 the effect of
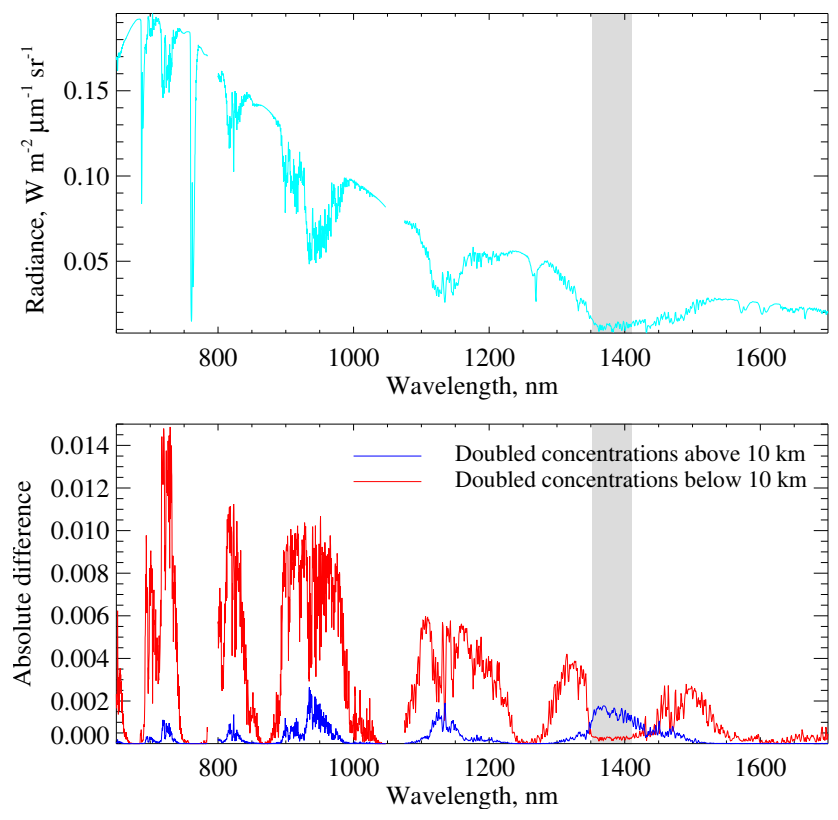

Fig. 1. Upper panel: simulated limb radiance in spectral channels 4, 5 , and 6 of SCIAMACHY at a tangent height of $12 \mathrm{~km}$. The spectral channels are separated by gaps. Lower panel: absolute differences in the simulated radiance due to doubling of water vapor amounts above (blue curve) and below (red curve) $10 \mathrm{~km}$. Positive differences mean that changes in the water vapor abundance lead to a decrease in the limb radiance. Grey shaded areas mark the spectral range that is found to be optimal for the UTLS water vapor retrieval.

stratospheric and tropospheric water vapor abundances upon the simulated limb radiance is illustrated. Absolute differences in the simulated radiance due to doubling of stratospheric (above $10 \mathrm{~km}$ ) and tropospheric (below $10 \mathrm{~km}$ ) water vapor amounts are depicted by blue and red curves, respectively. Positive differences mean a decrease in the simulated radiance with respect to the unperturbed simulation shown in the upper panel of the figure. The spectral interval for the retrieval is selected to ensure maximum response of the observed radiance to water vapor variations in the upper layers (i.e., above $10 \mathrm{~km}$ ) and minimum response to variations of the lower tropospheric water vapor (i.e., below $10 \mathrm{~km}$ ). The optimal spectral range marked in Fig. 1 by grey shadings is found to be between 1353 and $1410 \mathrm{~nm}$.

\subsection{Inversion technique}

In this study, vertical distributions of water vapor are retrieved employing the so-called global fit approach. The basic idea of this method is, first, to establish a linear relationship between measured radiances and atmospheric parameters to be retrieved, and then solve the obtained linear inverse problem employing a regularized least-square fit. A widely known implementation of the regularized least-square 
fit, commonly referred to as the optimal estimation method with the maximum a posteriori information, is discussed in detail by Rodgers (2000).

For atmospheric remote sensing observations a (nonlinear) relation between measured radiances and atmospheric parameters is provided by the radiative transfer equation which in the most general representation can be written as follows:

$\boldsymbol{y}=\boldsymbol{F}(\boldsymbol{x} ; \hat{\boldsymbol{x}})$,

where the mapping $\boldsymbol{F}$ represents the radiative transfer operator, also referenced as the forward model operator, $\boldsymbol{y}$ is the measurement vector, $\boldsymbol{x}$ is the state vector containing the atmospheric parameters to be retrieved, and $\hat{x}$ contains the parameters which affect the simulated radiance but can not be obtained from the measurements. A linearized radiative transfer equation is obtained employing the Taylor series expansion around an initial guess atmospheric state, $\boldsymbol{x}_{\mathrm{a}}$, (also referred to as the a priori state vector) which is the best beforehand estimator of the true solution. Neglecting the higher order terms in the Taylor series expansion, the following linear relation between measured radiances and atmospheric parameters to be retrieved is obtained:

$\boldsymbol{y}=\boldsymbol{F}\left(\boldsymbol{x}_{\mathrm{a}}\right)+\left.\frac{\partial \boldsymbol{F}(\boldsymbol{x})}{\partial \boldsymbol{x}}\right|_{\boldsymbol{x}=\boldsymbol{x}_{\mathrm{a}}} \times\left(\boldsymbol{x}-\boldsymbol{x}_{\mathrm{a}}\right)+\epsilon$,

where $\epsilon$ contains the linearization error, measurement errors, and error due to unknown atmospheric parameters which can not be retrieved. For simplicity reasons we assume here and everywhere below $\hat{\boldsymbol{x}}=\hat{\boldsymbol{x}}_{\mathrm{a}}$ and skip the explicit notation of the dependence on $\hat{\boldsymbol{x}}_{\mathrm{a}}$.

Neglecting all errors, the linearized inverse problem is written as

$\boldsymbol{y}=\boldsymbol{F}\left(\boldsymbol{x}_{\mathrm{a}}\right)+\mathbf{K}\left(\boldsymbol{x}-\boldsymbol{x}_{\mathrm{a}}\right)$,

where

$\left.\mathbf{K} \equiv \frac{\partial \boldsymbol{F}(\boldsymbol{x})}{\partial \boldsymbol{x}}\right|_{\boldsymbol{x}=\boldsymbol{x}_{\mathrm{a}}}$

is the Jacobian matrix also referred to as the weighting function matrix. The linear inverse ill-posed problem represented by Eq. (3) is solved in the least squares sense employing the generalized Tikhonov regularization:

$$
\left\|\boldsymbol{F}\left(\boldsymbol{x}_{\mathrm{a}}\right)+\mathbf{K}\left(\boldsymbol{x}-\boldsymbol{x}_{\mathrm{a}}\right)-\boldsymbol{y}\right\|_{\mathbf{P}}^{2}+\left\|\left(\boldsymbol{x}-\boldsymbol{x}_{\mathrm{a}}\right)\right\|_{\mathbf{Q}}^{2} \longrightarrow \min .
$$

Here, $\mathbf{Q}$ is a constraint matrix for the state vector and $\mathbf{P}$ (following notations from Rodgers, 2000; $\mathbf{P}=\mathbf{S}_{\varepsilon}^{-1}$ ) is the inverse error covariance matrix of the measurement vector $\boldsymbol{y}$. The matrix $\mathbf{S}_{\varepsilon}$ is often referred to as the noise covariance matrix. In the framework of the widely known optimal estimation method with the maximum a posteriori information, as described by Rodgers (2000), the state vector constraint matrix,
$\mathbf{Q}$, is represented by the inverse a priori covariance matrix, i.e., using the notations from Rodgers (2000) $\mathbf{Q}=\mathbf{S}_{\mathrm{a}}^{-1}$.

The solution of the linear inverse problem given by Eq. (5) is obtained as follows:

$\boldsymbol{x}=\boldsymbol{x}_{\mathrm{a}}+\left(\mathbf{K}^{T} \mathbf{P} \mathbf{K}+\mathbf{Q}\right)^{-1} \mathbf{K}^{T} \mathbf{P}\left(\boldsymbol{y}-\boldsymbol{F}\left(\boldsymbol{x}_{\mathrm{a}}\right)\right)$.

To account for the non-linearity of the inverse problem, the Gauss-Newton iterative approach is employed. At $(i+1)$-th iterative step this approach results in the following solution:

$$
\begin{aligned}
\boldsymbol{x}_{i+1}=\boldsymbol{x}_{\mathrm{a}}+\left(\mathbf{K}_{\mathrm{i}}^{T} \mathbf{P} \mathbf{K}_{i}+\mathbf{Q}\right)^{-1} \times \\
\mathbf{K}_{i}^{T} \mathbf{P}\left(\boldsymbol{y}-\boldsymbol{F}\left(x_{i}\right)+\mathbf{K}_{i}\left(\boldsymbol{x}_{i}-\boldsymbol{x}_{\mathrm{a}}\right)\right) .
\end{aligned}
$$

The iterative process is stopped if the maximum difference between the components of the solution vector at two subsequent iterative steps does not exceed $1 \%$. Typically 5-7 iterations are required to achieve convergence.

\subsection{Retrieval implementation and parameter settings}

The retrieval algorithm used in this study to gain vertical distributions of water vapor from SCIAMACHY limb measurements exploits the spectral information between 1353 and $1410 \mathrm{~nm}$. Summarizing the discussion in Sect. 3.1, usage of this spectral interval maximizes sensitivity to the stratospheric water vapor and reduces the influence of the lower troposphere. As pointed out in Sect. 2, a typical SCIAMACHY limb observation comprises a series of spectral measurements performed at tangent heights between about -3 and $100 \mathrm{~km}$. However, spectra at upper tangent heights are too noisy whereas measurements at lower tangent heights are contaminated by clouds and saturations effects. Therefore, only measurements at tangent heights between about 11 and $25 \mathrm{~km}$ are considered in the retrieval process. In addition to those from water vapor, absorption bands of methane are included in the fit procedure. Although the methane absorption is much weaker than that of the water vapor, this improves the spectral fits, especially at lower tangent heights. A reliable retrieval of methane is, however, not possible.

As implemented in many other retrieval algorithms, the inverse problem in this study is formulated for logarithms of measured radiances rather than radiances themselves. As shown in previous studies (Klenk et al., 1982; Hoogen et al., 1999; Rozanov and Kokhanovsky, 2008), this approach increases the linearity of the inverse problem resulting in smaller linearization errors. The solar Fraunhofer structure is accounted for by dividing limb spectra at each tangent height by the solar spectrum. The un-calibrated ASM diffuser solar spectrum is used for this purpose that is measured by SCIAMACHY once a day. This method is preferred to a widely used high tangent height reference because of a poor signal to noise ratio in near-infrared limb spectra observed above $25 \mathrm{~km}$. To reduce the influence of instrument 
calibration effects as well as broadband spectral features due to unknown atmospheric parameters such as surface albedo and aerosols only the differential absorption structure is considered in the retrieval. This is done by subtracting a cubic polynomial from all spectra used in the retrieval.

Following the discussion above, the measurement vector $\boldsymbol{y}$ is created by first taking the logarithms of the limb radiances and solar spectrum, then subtracting from the resulting spectra a cubic polynomial (by a least squares fit):

$\hat{I}_{\mathrm{n}}(\lambda)=\ln I_{\mathrm{n}}(\lambda)-\sum_{i=0}^{3} a_{\mathrm{n}, i} \lambda^{i} \quad n=1, \ldots, N$,

$\hat{I}_{\mathrm{sol}}(\lambda)=\ln I_{\mathrm{sol}}(\lambda)-\sum_{i=0}^{3} a_{\mathrm{sol}, i} \lambda^{i}$,

where $N$ is the number of tangent heights in the selected altitude region $(\sim 11-25 \mathrm{~km})$, and ratioing finally the detrended limb radiances to the detrended solar spectrum:

$y_{\mathrm{n}}(\lambda)=\hat{I}_{\mathrm{n}}(\lambda)-\hat{I}_{\mathrm{sol}}(\lambda)$.

The spectral signals $y_{\mathrm{n}}(\lambda)$ obtained in this way are often referred to as the differential logarithmic spectra or differential optical depths. Thus, the measurement vector $\boldsymbol{y}$ in Eq. (7) contains differential logarithmic signals at all spectral points between 1353 and $1410 \mathrm{~nm}$ obtained at all tangent heights between 11 and $25 \mathrm{~km}$ :

$\boldsymbol{y}=\left[y_{1}\left(\lambda_{1}\right), \ldots, y_{1}\left(\lambda_{L}\right), \ldots, y_{N}\left(\lambda_{1}\right), \ldots, y_{N}\left(\lambda_{L}\right)\right]^{T}$,

where $L$ is the number of spectral points in the considered spectral range (316 spectral points in 1353-1410 nm range).

Similarly to the measurement vector $\boldsymbol{y}$, the model vector $\boldsymbol{F}\left(x_{i}\right)$, which is the result of the radiative transfer operator applied to a known atmospheric state, contains differential logarithmic spectra of the simulated limb radiance at all considered tangent heights:

$$
\begin{aligned}
\boldsymbol{F}\left(x_{\dot{1}}\right)=\left[\hat{I}_{1}^{\operatorname{sim}}\left(\lambda_{1}\right), \ldots,\right. & \hat{I}_{1}^{\operatorname{sim}}\left(\lambda_{L}\right), \ldots, \\
& \left.\hat{I}_{N}^{\operatorname{sim}}\left(\lambda_{1}\right), \ldots, \hat{I}_{N}^{\operatorname{sim}}\left(\lambda_{L}\right)\right]^{T},
\end{aligned}
$$

where $\hat{I}_{n}^{\text {sim }}(\lambda)$ is obtained from the simulated limb radiance, $I_{n}^{\operatorname{sim}}(\lambda)$, in exactly the same way as described by Eq. (8) for the measured limb radiance. As above, the simulations are done assuming the extraterrestrial solar flux to be equal to $\pi \mathrm{W} \mathrm{m}^{-2} \mu \mathrm{m}^{-1}$.

To ensure that the resulting vertical profiles are always non-negative, the inverse problem given by Eq. (3) is solved for logarithms of trace gas number densities instead of the number densities themselves, i.e., the state vector $\boldsymbol{x}$ contains logarithms of water vapor and methane number densities at all altitude levels considered in the forward model.

Although the spectral interval used in this study is selected to reduce the influence of the lower tropospheric water vapor, under certain conditions, its contribution to the measured signal can still remain non-negligible (see Sect. 4.1 for details). To account for this contribution, two additional components are appended to the state vector, namely, the tropospheric contribution parameter, $t$, and the surface albedo, $A$. Depending on the retrieval iteration, the former represents either the scaling factor for the tropospheric water vapor profile or the surface elevation. In addition, a possible influence of the stratospheric aerosols (see Sect. 4.5 for details) is accounted for including a scaling factor, $e$, for the vertical profile of the stratospheric aerosol extinction coefficient.

Summing up the discussion above, the state vector is written as

$$
\begin{array}{r}
\boldsymbol{x}=\left[\ln p_{\mathrm{w}}\left(z_{1}\right), \ldots, \ln p_{\mathrm{w}}\left(z_{J}\right),\right. \\
\left.\ln p_{\mathrm{m}}\left(z_{1}\right), \ldots, \ln p_{\mathrm{m}}\left(z_{J}\right), t, A, e\right]^{T},
\end{array}
$$

where $p_{\mathrm{w}}(z)$ and $p_{\mathrm{m}}(z)$ are the number densities of the water vapor and methane, respectively, $z$ is the altitude grid of the forward model, and $J$ is the total number of the altitude levels. In the altitude range relevant for the water vapor retrieval an equidistant height grid with $1 \mathrm{~km}$ spacing is used.

The weighting function matrix $\mathbf{K}$ describes variations of the radiance logarithms at considered tangent heights and spectral points due to variations of the retrieved parameters (water vapor and methane number densities at different altitude levels, tropospheric contribution, surface albedo, and scaling factor for stratospheric aerosol extinction). Similarly to the measurement vector $\boldsymbol{y}$ and model vector $\boldsymbol{F}\left(x_{\mathrm{i}}\right)$, the weighting functions need to be transformed into the differential logarithmic representation. Taking into account Eq. (4) this is done as follows:

$$
\begin{aligned}
K_{\mathrm{n}, j}(\lambda)=\frac{1}{I_{\mathrm{n}}^{\operatorname{sim}}(\lambda)} \frac{\partial I_{\mathrm{n}}^{\operatorname{sim}}(\lambda)}{\partial x_{j}}-\sum_{i=0}^{3} a_{\mathrm{n}, i} \lambda^{i}, \\
n=1, \ldots, N, \quad j=1, \ldots, 2 J+3,
\end{aligned}
$$

where $x_{j}$ are the components of the state vector $\boldsymbol{x}$ as defined by Eq. (12). The row index of the matrix elements is running with the spectral point number and with the tangent height similar to the measurement vector, see Eq. (10). The column index is running with the retrieval parameter number (altitude layers for the water vapor and methane, tropospheric contribution, surface albedo, and scaling factor for stratospheric aerosol extinction) similar to the state vector, see Eq. (12).

Synthetic limb radiance spectra as well as appropriate weighting functions are calculated with the SCIATRAN radiative transfer model (Rozanov et al., 2005; Rozanov, 2011) taking into account refractive ray tracing. The limb radiance is simulated in the approximate spherical mode employing the combined differential-integral approach. In the framework of this method the single scattering contribution is treated fully spherically. For the multiply scattered light, a pseudo-spherical model is used first to obtain the multiple 
scattering source function at each point along the instrument line of sight. Doing this, the solar zenith angle and viewing direction are set in accordance with a spherical ray tracing. Finally, the multiple scattering contributions are integrated along the line of sight taking into account the sphericity of the atmosphere. A detailed description of this approach is presented by Rozanov et al. (2001). Weighting functions for trace gas number densities are calculated solving the linearized radiative transfer equation (Rozanov and Rozanov, 2007) in the single scattering approximation. It is worth noting here that the single scattering approximation means that contributions of all atmospheric layers below the instrument field of view (i.e., contributions of the lower tropospheric water vapor) are neglected and the corresponding elements of the weighting function matrix are zero. Obviously, this method is unsuitable to account for tropospheric or surface parameters. Therefore, the numerical perturbation method is used to obtain weighting functions for the tropospheric contribution and for the surface albedo. The weighting function for the stratospheric aerosol extinction is also calculated by the numerical perturbation method.

Before the main retrieval is performed, all spectra are corrected for a possible wavelengths misalignment that can be caused by a changing illumination of the instrument entrance slit during the vertical scan. This is done for each tangent height independently minimizing the following quadratic form with respect to parameters $s_{i}, c_{\mathrm{sim}}$, and $c_{\mathrm{sol}}$ :

$$
\begin{aligned}
& \| \hat{I}_{\mathrm{n}}(\lambda)-\hat{I}_{\mathrm{sol}}(\lambda)-\hat{I}_{n}^{\operatorname{sim}}(\lambda)-\sum_{i=1}^{4} s_{i} W_{\mathrm{n}, i}(\lambda)- \\
& c_{\mathrm{sim}} \frac{\partial \hat{I}_{\mathrm{n}}^{\operatorname{sim}}(\lambda)}{\partial \lambda}-c_{\mathrm{sol}} \frac{\partial \hat{I}_{\mathrm{sol}}(\lambda)}{\partial \lambda} \|^{2} \rightarrow \min .
\end{aligned}
$$

Here, the weighting functions for water vapor and methane number densities are vertically integrated, e.g., for water vapor

$$
W_{n, 1}(\lambda)=\sum_{j=1}^{J} K_{n, j}(\lambda) \Delta z_{j},
$$

where $K_{n, j}(\lambda)$ is defined according to Eq. (13), whereas the weighting functions for the tropospheric contribution, surface albedo, and stratospheric aerosol extinction are kept unchanged, e.g.,

$$
W_{n, 3}(\lambda)=K_{n, 2 J+1}(\lambda) .
$$

The coefficients $c_{\text {sim }}$ and $c_{\text {sol }}$ represent shift corrections for the simulated and the solar spectrum with respect to the measured spectrum, respectively. As the simulated spectrum contains only atmospheric absorption features and the irradiance spectrum is dominated by solar Fraunhofer structure, the shift corrections are uncorrelated. Although the fit parameters are tangent height dependent, subscript $n$ is omitted here for simplicity.
The shift coefficients obtained from this spectral fit are used to correct spectral misalignments of the simulated and solar spectra as follows:

$\hat{I}_{n}^{\operatorname{sim}}(\lambda)=\hat{I}_{n}^{\operatorname{sim}}(\lambda)+c_{\operatorname{sim}} \frac{\partial \hat{I}_{n}^{\operatorname{sim}}(\lambda)}{\partial \lambda}$

and

$\hat{I}_{\mathrm{sol}}(\lambda)=\hat{I}_{\mathrm{sol}}(\lambda)+c_{\mathrm{sol}} \frac{\partial \hat{I}_{\mathrm{sol}}(\lambda)}{\partial \lambda}$.

These corrected spectra are used then to create the measurement and model vectors as defined by Eqs. (9) and (11), respectively. The scaling factors $s_{i}$ are auxiliary parameters that are not used further.

In the course of the main retrieval procedure, the nonlinear inverse problem defined by Eq. (1) is solved according to Eq. (7) with weighting function matrix defined by Eq. (13) and measurement, model, and state vectors defined by Eqs. (10), (11), and (12), respectively. The noise covariance and solution constraint matrices ( $\mathbf{P}$ and $\mathbf{Q}$, respectively) are set up as described below.

The diagonal elements of the noise covariance matrix, $\mathbf{P}$, are set according to root mean squares of the fit residuals obtained minimizing the quadratic form given by Eq. (14) at each tangent height. The off-diagonal elements of this matrix are set to zero assuming the measurement noise to be spectrally uncorrelated. The solution constraint matrix, $\mathbf{Q}$, consist of two matrices, namely, the inverse a priori covariance matrix as commonly used in the optimal estimation approach (Rodgers, 2000) and a smoothness constraint matrix:

$\mathbf{Q}=\mathbf{S}_{\mathrm{a}}^{-1}+\mathbf{R}^{T} \mathbf{R}$.

The usage of smoothness constraints is advantageous to suppress oscillations of the solution without overconstraining it when retrieving at a fine altitude grid.

For each atmospheric species included in the retrieval (water vapor and methane), the elements of the a priori covariance matrix are set in accordance with the following rule:

$\left\{S_{\mathrm{a}}\right\}_{i, j}=\sigma_{i} \sigma_{j} \exp \left(-\frac{\left|z_{i}-z_{j}\right|}{l_{\mathrm{c}}}\right)$,

where $\sigma_{i}$ and $\sigma_{j}$ are a priori uncertainties at altitudes $z_{i}$ and $z_{j}$, respectively, and $l_{\mathrm{c}}$ is the correlation length (set to $1.5 \mathrm{~km}$ in this study). The full a priori covariance matrix is formed then from the covariance matrices of both species as well as covariances of the tropospheric contribution, $\sigma_{t}^{2}$, of the surface albedo, $\sigma_{A}^{2}$, and of the stratospheric aerosol extinction, $\sigma_{\mathrm{e}}^{2}$ :

$\mathbf{S}_{\mathrm{a}}=\left[\begin{array}{cccccc}\mathbf{S}_{\mathrm{a}}^{\mathrm{H}_{2} \mathrm{O}} & \mathbf{0} & \mathbf{0} & \mathbf{0} & \mathbf{0} \\ \mathbf{0} & \mathbf{S}_{\mathrm{a}}^{\mathrm{CH}_{4}} & \mathbf{0} & \mathbf{0} & \mathbf{0} \\ \mathbf{0} & \mathbf{0} & \sigma_{t}^{2} & 0 & 0 \\ \mathbf{0} & \mathbf{0} & 0 & \sigma_{A}^{2} & 0 \\ \mathbf{0} & \mathbf{0} & 0 & 0 & \sigma_{\mathrm{e}}^{2}\end{array}\right]$, 

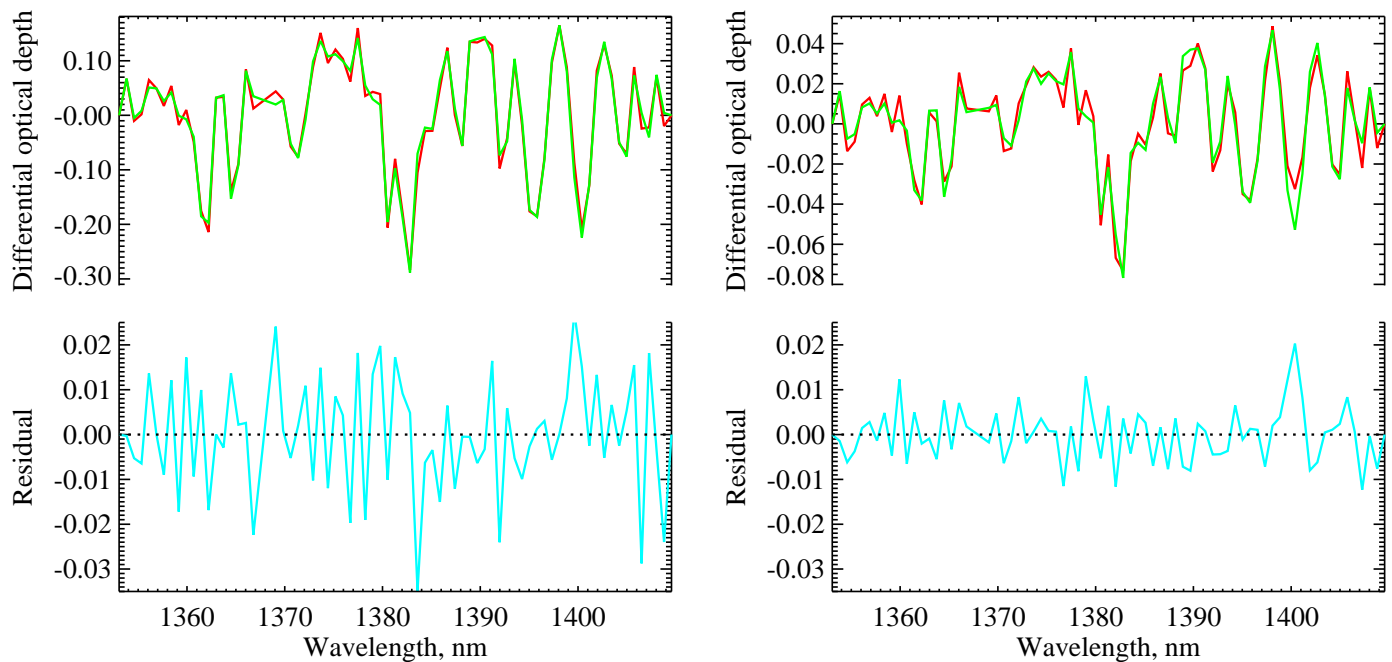

Fig. 2. Example spectral fits for tangent heights of $12 \mathrm{~km}$ (left panels) and $21.9 \mathrm{~km}$ (right panels). The upper panels show measured (red) and simulated (green) differential logarithmic spectra whereas the lower panels show fit residuals. The results are obtained for a SCIAMACHY limb measurement performed on 27 January 2004, at 17:18:22 UTC (orbit 9986) over Boulder, CO, USA $\left(40^{\circ} \mathrm{N}, 105^{\circ} \mathrm{W}\right.$ ).

where 0 represents a zero submatrix. Cross-correlations between different species, tropospheric contribution, surface albedo, and stratospheric aerosol extinction are not considered. A priori uncertainties are set to $300 \%$ for water vapor, $30 \%$ for methane, 0.1 for the surface albedo, and $30 \%$ for the stratospheric aerosol extinction.

In the current implementation of the retrieval, the tropospheric contribution is accounted for by fitting first the surface elevation with a priori uncertainty of $3 \mathrm{~km}$ until a convergence within $500 \mathrm{~m}$ is obtained and then by scaling the tropospheric water vapor profile with a priori uncertainty of $100 \%$. The initial guess for the surface elevation is set to $3 \mathrm{~km}$. This approach is favorable because both surface elevation and tropospheric scaling are quite well uncorrelated with the surface albedo whereas fitting all three parameters together might cause retrieval instability. As mentioned above, trace gas weighting functions are calculated in a single scattering approximation, thus they contain no contribution form the tropospheric part of the water vapor profile. This allows the retrieval algorithm to distinguish well between the profile and the tropospheric scaling.

Similarly to the a priori covariance matrix, matrix $\mathbf{R}$ is also block diagonal. It contains, however, zeros in place of the altitude independent parameters (tropospheric contribution, surface albedo, and stratospheric aerosol extinction):

$\mathbf{R}=\left[\begin{array}{ccc}\mathbf{R}^{\mathrm{H}_{2} \mathrm{O}} & \mathbf{0} & \mathbf{0} \\ \mathbf{0} & \mathbf{R}^{\mathrm{CH}_{4}} & \mathbf{0} \\ \mathbf{0} & \mathbf{0} & \mathbf{0}\end{array}\right]$

Non-zero elements of the submatrices for each particular species are given by

$$
\{\mathbf{R}\}_{j, j-1}=\frac{c_{j}}{z_{j-1}-z_{j}} \quad \text { and } \quad\{\mathbf{R}\}_{j, j}=\frac{-c_{j}}{z_{j-1}-z_{j}},
$$

where $c_{j}$ represents the smoothness coefficient and $j$ runs through all altitude levels starting from the second one. For water vapor, the smoothness coefficient increases linearly from 5 at $10 \mathrm{~km}$ to 10 at $30 \mathrm{~km}$, while smoothness coefficient of 1 is used at all altitude layers for methane.

Unlike the number densities of water vapor and methane, the a priori information for tropospheric contribution, surface albedo, and stratospheric aerosol extinction is replaced at each iterative step by the results from the previous iteration. This method on the one hand stabilizes the retrieval allowing the use of relatively small covariances, on the other hand it allows arbitrary large deviations of the retrieved parameters from the initial guess.

The spectral absorption features of the water vapor and methane are accounted for employing the correlated-k distribution technique (Buchwitz et al., 2000) with ESFT (exponential-sum fitting of transmissions) coefficients calculated using the HITRAN 2008 database (Rothman et al., 2009). This study uses 10 coefficients pre-calculated at 20 pressure and 9 temperature grid points for $0.2 \mathrm{~nm} \mathrm{spec-}$ tral bins. Comparisons with line-by-line calculations show that this setup ensures an average retrieval accuracy of better then $2 \%$. The forward model is initialized using the global pressure and temperature information provided by the European Centre for Medium-Range Weather Forecasts (ECMWF) as well as trace gas vertical distributions according to the US Standard 1976 model atmosphere (Committee on Extension to the Standard Atmosphere, 1976). The stratospheric aerosols are assumed to be non-absorbing. The vertical profile of the aerosol extinction coefficient is estimated by fitting radiance profiles averaged around 1090 and $1552 \mathrm{~nm}$. The wavelengths for the aerosol retrieval are selected to ensure a weak absorption by atmospheric trace gases. The 


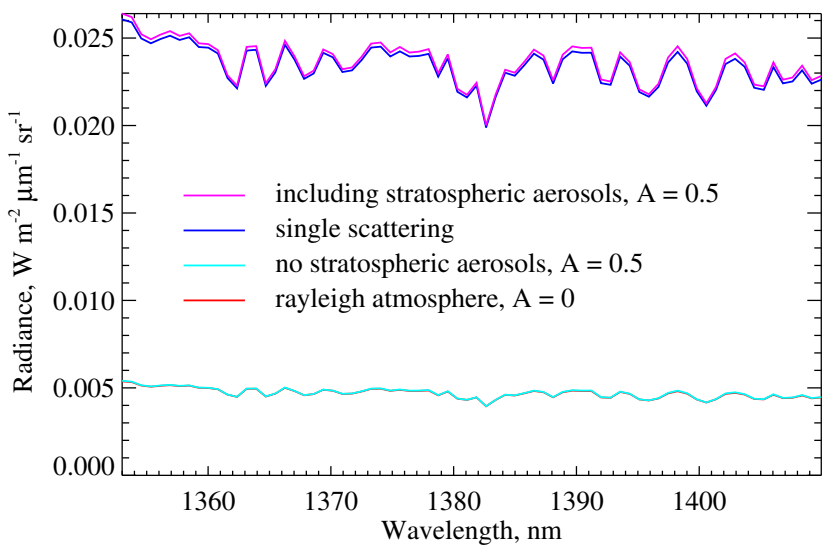

Fig. 3. Simulated limb radiance at a tangent height of $15 \mathrm{~km}$, a solar zenith angle of $69^{\circ}$, and a relative azimuth angle of about $40^{\circ}$ (both angles are defined at the tangent point). Magenta line: standard simulation considering multiple scattering, background aerosols, and surface albedo of 0.5 . Blue line: single scattering approximation including background aerosols. Cyan line: multiple scattering without stratospheric aerosols (above $10 \mathrm{~km}$ ) with surface albedo set to 0.5 . Red line (barely seen below the cyan line): Rayleigh scattering (including multiple scattering) with surface albedo set to 0 .

phase function is set according to the LOWTRAN background aerosol (Kneizys et al., 1986). The vegetation and land-use data base described by Matthews (1983) is used to select an initial value for the surface albedo. In the current study, only limb scans with no clouds detected above $10 \mathrm{~km}$ are considered (see Sect. 4.4 for details).

Figure 2 shows example spectral fits for a SCIAMACHY limb observation performed on 27 January 2004, at 17:18:22 UTC (orbit 9986) over Boulder, CO, USA $\left(40^{\circ} \mathrm{N}\right.$, $\left.105^{\circ} \mathrm{W}\right)$. The spectral fits are shown for tangent heights of 12 and $21.9 \mathrm{~km}$ in the left and right plots, respectively. The upper panels of each plot show the measured differential logarithmic spectra as defined by Eq. (9) by red curves and the corresponding simulated spectra by green curves whereas the lower panels show fit residuals.

\section{Sensitivity studies}

\subsection{Origin of the observed signal}

This section is intended to answer the question where the scattered light detected by the SCIAMACHY instrument during a limb observation originates from. Main topics to be investigated here are the role of stratospheric aerosols, contribution due to the multiple scattering, as well as the influence of the lower atmospheric composition (below the instrument field of view) and surface properties. At first, the most typical limb observations are discussed. These are considered to be performed over regions with not too dry troposphere, surface

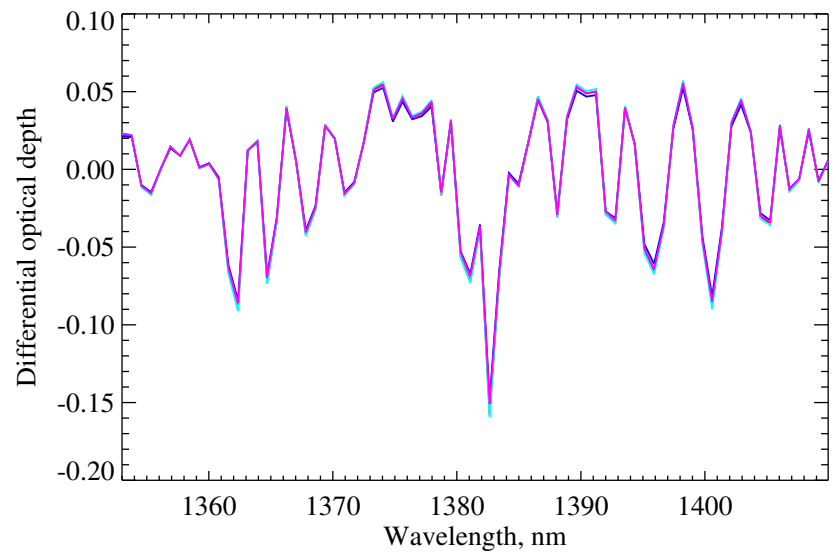

Fig. 4. Same as Fig. 3 but for differential logarithmic intensities (differential optical depths). The curves for all considered cases are very similar and barely seen below the magenta line.

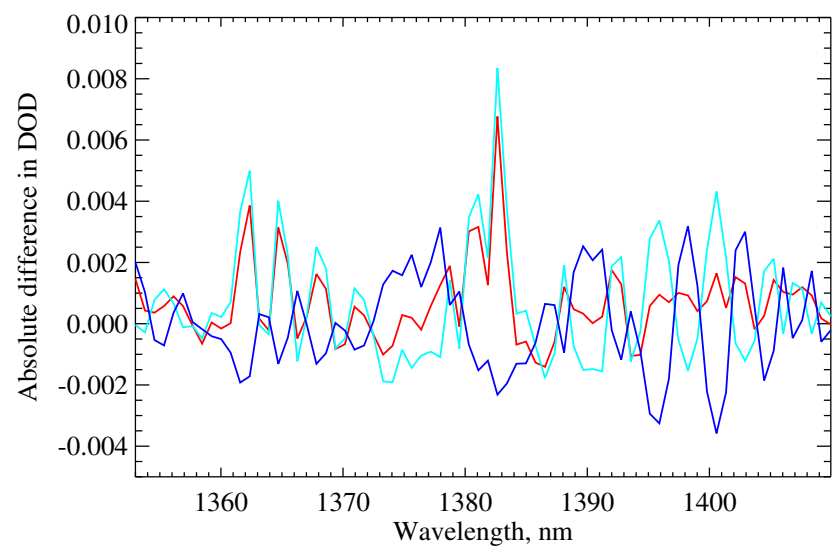

Fig. 5. Absolute differences in the differential optical depths (DOD) shown in Fig. 4 with respect to the standard scenario. The color coding is the same as in Figs. 3 and 4.

height at about see level, and no highly reflecting thick clouds below the instrument field of view. Special cases where some of this requirements are not fulfilled are discussed in the second part of this section as well as in Sect. 4.3 below.

Figure 3 shows synthetic limb radiance simulated assuming different atmospheric compositions. The incident solar flux is assumed to be equal $\pi \mathrm{W} \mathrm{m}^{-2} \mu \mathrm{m}^{-1}$. The simulations are performed for a tangent height of $15 \mathrm{~km}$, a solar zenith angle of $69^{\circ}$, and a relative azimuth angle of about $40^{\circ}$ (both angles are defined at the tangent point). Results of the standard run considering multiple scattering, background aerosols, and a surface albedo of 0.5 are shown by the magenta line. The same simulation in single scattering approximation is shown by the blue line. Both curves lie close together indicating that the bulk of the observed limb signal is due to single scattering. Coming back to the multiply scattered radiation and turning off the stratospheric aerosols (above $10 \mathrm{~km}$ ) the results depicted by the 

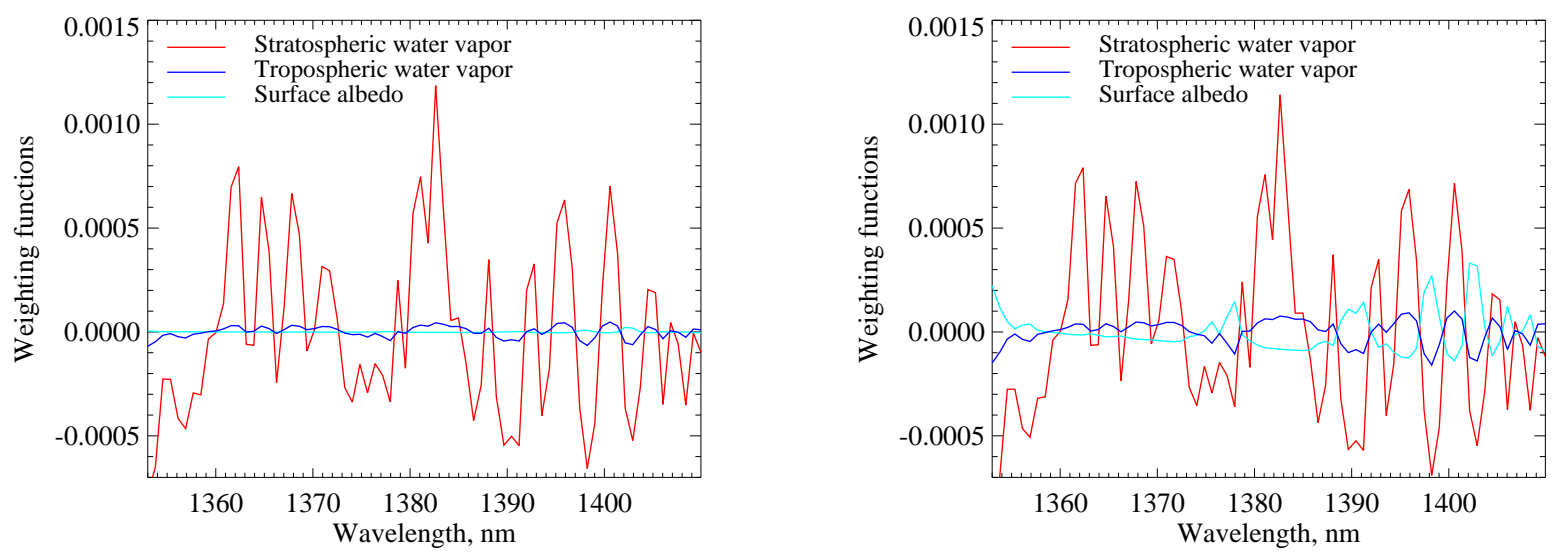

Fig. 6. Weighting functions for the stratospheric water vapor (red), tropospheric water vapor (blue), and surface albedo (cyan) for a typical SCIAMACHY limb observation (left panel) and for a surface elevation of $2 \mathrm{~km}$ (right panel).

cyan line are obtained. A strong decrease in the intensity reveals that aerosol scattering dominates in the considered spectral range. Finally, the red line (barely seen below the cyan line) shows the synthetic limb radiance simulated for an aerosol-free atmosphere and non-reflecting surface (surface albedo is set to zero). This scenario represents a simulation with a strongly reduced contribution of light scattered in the lower atmosphere and/or reflected from the surface. As expected, for a typical SCIAMACHY observation the influence of the lower atmospheric composition and surface properties upon the simulated radiance is rather small.

Being crucial for absolute values of the limb radiance, the exact knowledge of aerosol scattering characteristics plays, however, a rather minor role when simulating differential absorption. This is illustrated in Fig. 4 where the same simulated radiances as in Fig. 3 are shown in the differential logarithmic representation as defined by Eq. (8). One sees that the spectral signals do not differ much any more. Absolute differences in the differential logarithmic intensities with respect to the standard scenario (shown with the magenta line in Figs. 3 and 4) are presented in Fig. 5. Here, the same color coding as above is used. The plot reveals that all considered parameters cause differences of similar magnitude which amounts to about 5-10\% of the observed signal (as shown in Fig. 4).

The overall behavior observed in Figs. 3-5 remains nearly the same for other observation geometries (not shown here), e.g., for small solar zenith angles and scattering angles about $90^{\circ}$ typical for tropical observations or large solar zenith angles and backward scattering typical for high latitudes of the Southern Hemisphere. The only significant difference is seen in absolute values of the limb radiance simulated including stratospheric aerosols (blue and magenta curves in Fig. 3).

For a typical SCIAMACHY limb observation most of the solar light penetrating into the lower troposphere is absorbed. Much more light can be scattered back into the instrument field of view if the water vapor absorption in the lower tro- posphere is abnormally weak. This can be the case, for example, for an extremely dry troposphere or highly reflecting surfaces with high elevations above the sea level (mountains, clouds). Under these circumstances, the portion of light in the observed limb signal that has traveled long paths through the lower troposphere increases. Consequently, a stronger influence of the lower tropospheric composition and surface properties upon the retrieval is expected. This fact is illustrated in Fig. 6 that shows the weighting function for the stratospheric water vapor column (red curves) in comparison with the weighting functions for the tropospheric water vapor column (blue curves) and for the surface albedo (cyan curves). Here, the former weighting function is defined by Eq. (15) while the latter two are according to Eq. (16). Similar to previous plots, the weighting functions are calculated for a tangent height of $15 \mathrm{~km}$ and a solar zenith angle of $69^{\circ}$. The left panel represents a typical SCIAMACHY limb observation while the right panel depicts a case of an abnormally weak absorption in the lower troposphere due to a reflecting surface elevated by $2 \mathrm{~km}$ a.s.l. (above the sea level). As discussed above, weighting functions describe variations of the observed signal due to variations in atmospheric or surface properties. Thus, a larger weighting function denotes higher influence of the corresponding parameter upon the observed signal and, consequently, upon the retrieved profiles. For a typical SCIAMACHY limb observation, Fig. 6 reveals a minor role of both tropospheric water vapor column and surface albedo as their weighting functions are negligibly small in comparison with the weighting function of the stratospheric water vapor column. In contrast, for a highly elevated reflecting surface, magnitudes of all weighting functions become comparable indicating a stronger influence of the lower tropospheric composition and surface properties. The weighting function for the surface elevation behaves similar to both tropospheric water vapor column and surface albedo weighting functions and is not shown here for the sake of readability of the plots. To account for the influence of 


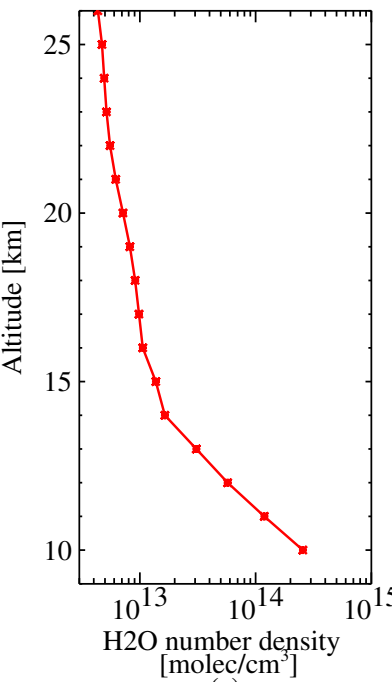

(a)

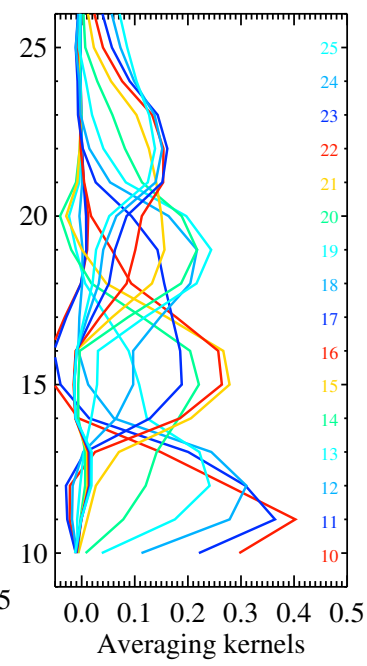

(b)

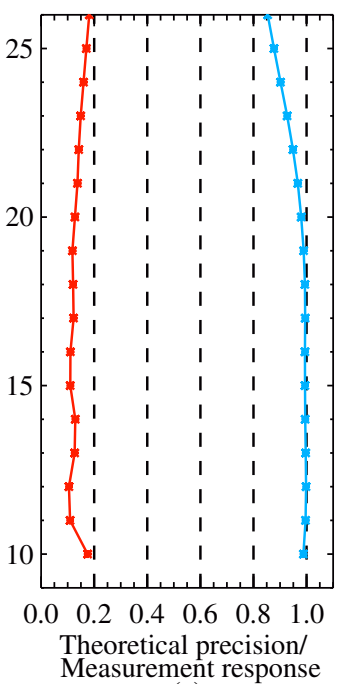

(c)

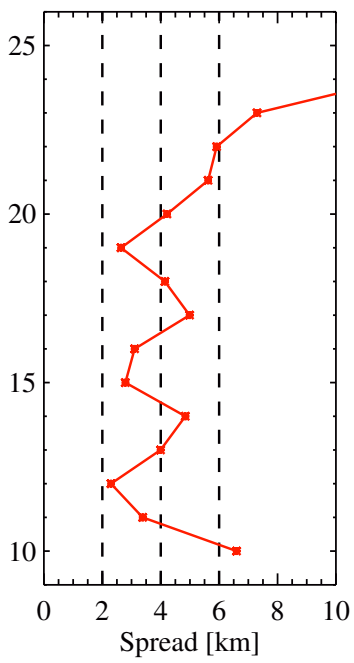

(d)

Fig. 7. Characterization of the water vapor retrieval for a typical observation in winter over Boulder, CO, USA: (a) vertical distribution of the water vapor number density measured by SCIAMACHY, (b) averaging kernels, (c) theoretical precision of the retrieval (red) and measurement response function (light blue), (d) spread of the averaging kernels.

the tropospheric composition and surface properties, the corresponding weighting functions are included in the retrieval procedure as discussed above in Sect. 3.3. More quantitatively the impact of the lower tropospheric composition and surface properties upon the retrieved water vapor profiles as well as remaining retrieval errors are discussed in Sect. 4.3.

\subsection{General characterization of the retrieval}

A commonly used approach to characterize retrieval algorithms that employ an optimal estimation type inversion is to analyze the averaging kernels. The latter are specific to the measurement setup, algorithm implementation, and retrieval parameter settings. For observations of the scattered solar light performed by space-borne instruments in limb viewing geometry, averaging kernels in the relevant altitude region are distinctly peaked at altitudes where a bulk of information is originating from. The shape of averaging kernels provides an information on the vertical sensitivity and resolution of the measurement-retrieval system as well as on the contribution of a priori information to retrieved profiles.

Figure 7 shows parameters essential for the retrieval characterization for a limb observation performed in winter over Boulder, CO, USA $\left(39.95^{\circ} \mathrm{N}, 105.2^{\circ} \mathrm{W}\right)$ at a solar zenith angle of about $65^{\circ}$. Panel (a) shows a water vapor number density profile typical for this location and season (measured by SCIAMACHY). The corresponding averaging kernels are shown in panel (b). The colored numbers in the right-hand side of the averaging kernel plot denote the altitudes for which the averaging kernels are calculated. The averaging kernels for altitudes close to measurement tangent heights show well pronounced peaks near the tangent point altitude. On the contrary, the averaging kernels for intermediate altitude levels are substantially broader with much less distinct peaks indicating a vertical redistribution of the information (strong influence of the neighboring altitude levels). The altitude region where the retrieval has the best sensitivity can be identified as 11 to $23 \mathrm{~km}$. Here, the averaging kernels are large and peak at their nominal altitudes. At higher altitudes the averaging kernels become broader which is associated with the smoothing error increasing with the altitude. The peak altitudes remain around $22 \mathrm{~km}$ almost independent of the nominal altitude of the averaging kernels which indicates that the water vapor signal observed at tangent heights above $23 \mathrm{~km}$ originates mostly from the lower layers. Bellow $11 \mathrm{~km}$, the averaging kernels still have pronounced peaks which, however, are clearly displaced upwards indicating that information from upper altitudes dominates the retrieved profile.

More quantitative characterization of the inversion quality can be done by looking at the theoretical precision of the retrieval and the measurement response function. The former is given by the square root of the diagonal elements of the solution covariance matrix (Rodgers, 1976, 1990) and describes the total retrieval error (i.e., sum of the noise and smoothing errors). The measurement response function is given by the area of the averaging kernels and describes the relative contribution of the measurements and a priori information to the retrieved profile. Values close to one indicate that most of the information comes from the measurement and the corresponding retrieval can be considered to be unbiased by a priori information. Both the theoretical precision (red curve) and measurement response function (light blue curve) are shown in panel (c) of Fig. 7. The theoretical precision 

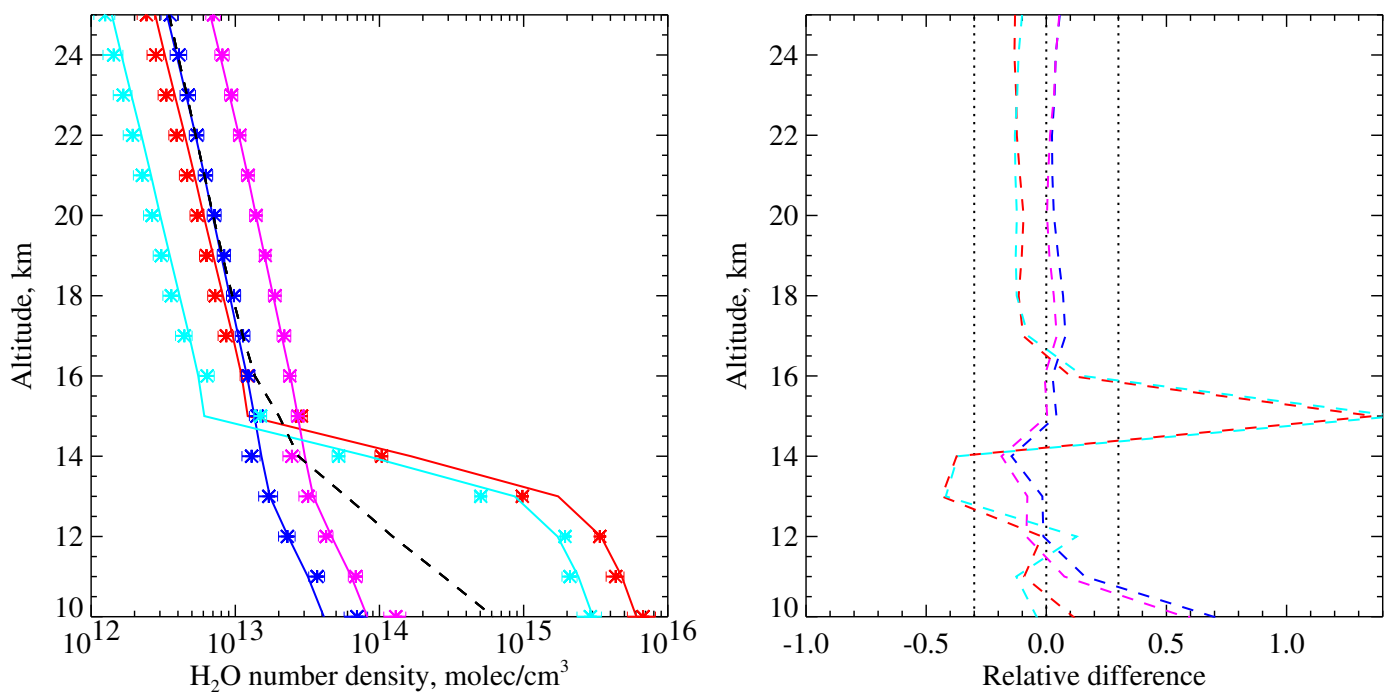

Fig. 8. Results of synthetic retrievals for different shapes of the true water vapor profile. Left panel: true (solid color lines), retrieved (asterisks), and a priori (dashed black line) water vapor profiles for different runs. Right panel: relative differences between the retrieved and true water vapor profiles (retrieved/true -1$)$.

of the retrieval is between 10 and $20 \%$ in the entire altitude range covered by the retrieval. The measurement response is close to 1 at all altitudes below $21 \mathrm{~km}$ slightly decreasing above.

The vertical resolution of the retrieval is characterized by the width of the averaging kernels which, however, is rather difficult to define quantitatively. Following other authors, e.g., Haley et al., 2004; Sofieva et al., 2004; Krecl et al., 2006, we employ the Backus and Gilbert approach (Backus and Gilbert, 1970) that suggests the so-called spread function to define the averaging kernel width:

$s(z)=12 \frac{\int\left(z-z^{\prime}\right)^{2} \mathbf{A}^{2}\left(z, z^{\prime}\right) d z^{\prime}}{\left[\int\left|\mathbf{A}\left(z, z^{\prime}\right)\right| d z^{\prime}\right]^{2}}$.

Panel (d) of Fig. 7 shows a typical spread function calculated according to Eq. (24) for the averaging kernels plotted in panel (b). It follows that, in the high sensitivity altitude range, the vertical resolution of the retrieval is about 2 to $3 \mathrm{~km}$ near the measurement tangent point altitudes and ranges between 4 and $6 \mathrm{~km}$ for intermediate layers. Above $23 \mathrm{~km}$ where the sensitivity of the measurements starts to decrease a stronger smoothing occurs leading to a rapid decrease of the vertical resolution. It is also worth noting that above $23 \mathrm{~km}$ the averaging kernel peaks are displaced from their nominal altitudes. The peak displacement increases the spread calculated according to Eq. (24) significantly. This is why the apparent width of the averaging kernels is no longer related to their spread and it becomes questionable if the Backus and Gilbert approach can still be used to characterize the vertical resolution of the retrieval.

Another way to investigate the retrieval performance is to simulate limb observations assuming different vertical dis- tributions of the water vapor and then perform synthetic retrievals with the same a priori information as in real retrievals. The results of these synthetic retrievals are shown in Fig. 8. In the left panel of the plot the true water vapor profiles used for simulations are depicted by colored solid lines whereas the retrieved profiles are shown by the asterisks of the corresponding colors. The dashed black line depicts the a priori profile. The true profiles shown by the blue and red lines are obtained from a climatological model for a winter season at latitudes of $35^{\circ} \mathrm{N}$ and $65^{\circ} \mathrm{N}$, respectively, whereas the profiles shown by the magenta and light blue lines are obtained scaling the above described climatological profiles. The scaling factors of 2 and 0.5 , respectively, are selected arbitrarily. The right panel of Fig. 8 shows the relative differences between the retrieved and true profiles of the water vapor. Here and everywhere below the relative differences are defined as "retrived/true - 1". For smooth true profiles (as shown by blue and magenta lines) the retrieval errors are mostly below $10 \%$ within the sensitivity range. A quite different behavior is observed for true profiles having sharp vertical gradients in the tropopause region. Due to a lack of the vertical resolution the break-points can not be captured exactly which leads to large local differences around the tropopause altitude and cause follow-up discrepancies at other altitudes. A usual way to account for different vertical resolutions of the compared profiles is to convolve highly resolved profiles with the averaging kernels corresponding to the low resolution retrieval. Convolving the true profiles shown in Fig. 8 with the corresponding averaging kernels the results shown in Fig. 9 are obtained. Now, true and retrieved profiles agree within $10 \%$ in the entire altitude range demonstrating that the discrepancies seen in Fig. 8 are mostly due 

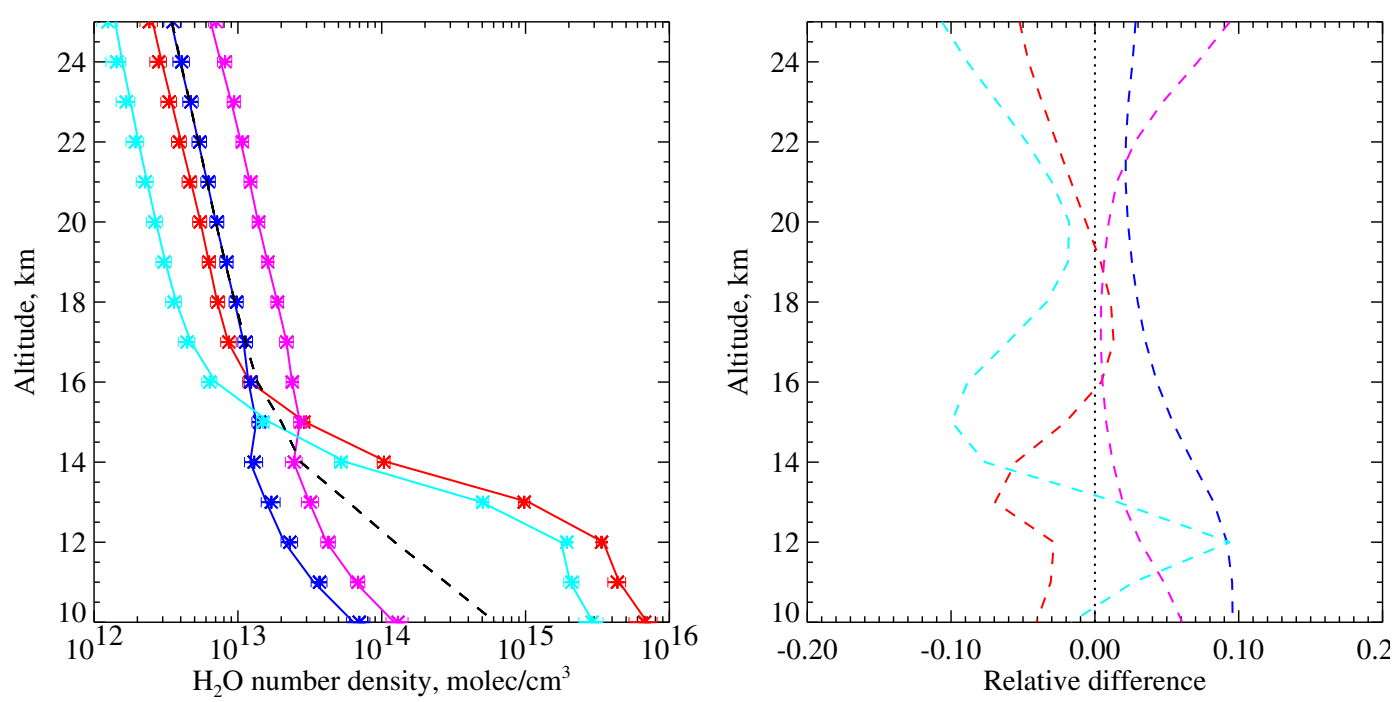

Fig. 9. Same as Fig. 8 but for the true profiles convolved with the corresponding averaging kernels.
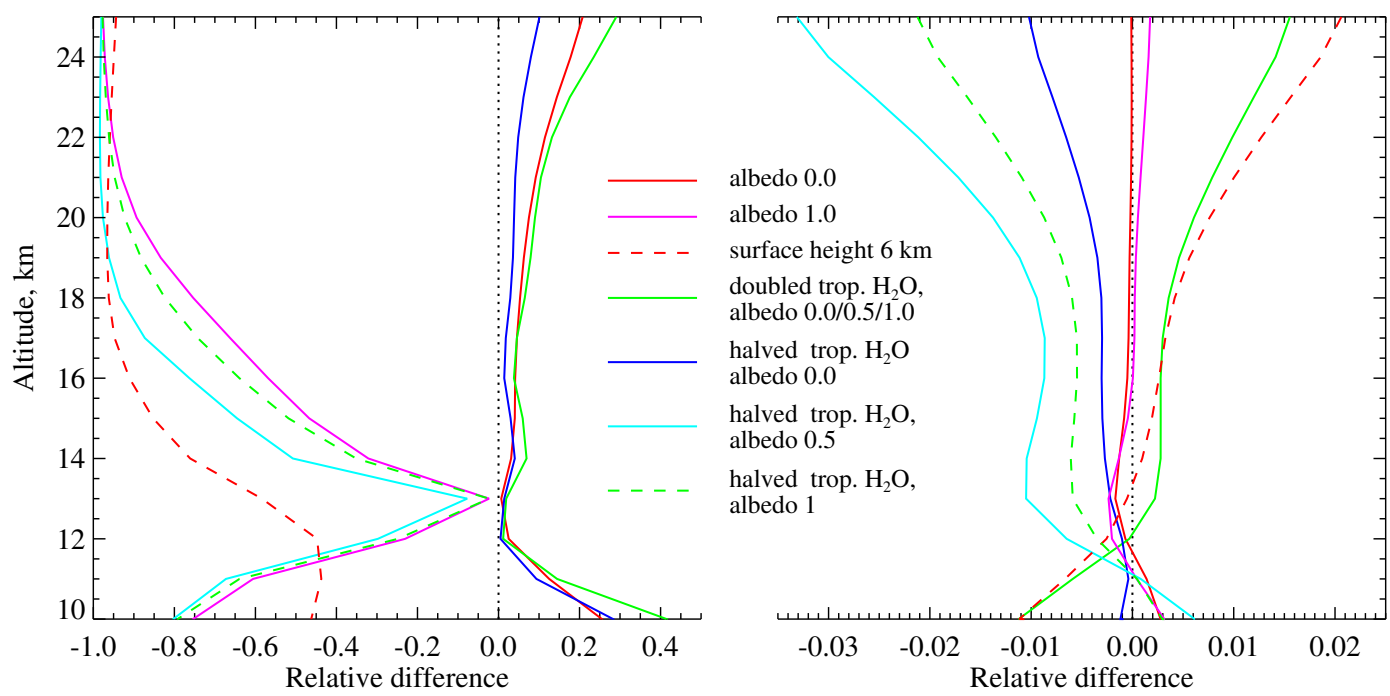

Fig. 10. Relative retrieval errors due to unknown atmospheric or surface parameters considering (right panel) and neglecting (left panel) the underlying scene in the retrieval process. See text for details.

to the limited vertical resolution of SCIAMACHY limb observations.

\subsection{Tropospheric impact and surface effects}

As discussed in Sect. 4.1, the impact of the lower tropospheric composition and surface properties upon the retrieved water vapor profiles is negligible for a typical limb observation. However, it may become significant if abnormally much light that has traveled long paths through the lower atmosphere reaches the detector. In this section we consider an example retrieval for a highly elevated surface to quantify the retrieval errors due to the lower tropospheric water vapor amount and surface properties. As illustrated below, reliable results in this case can only be obtained considering these parameters in the retrieval process.

The effect of the tropospheric water vapor amount and of the surface parameters is investigated performing synthetic retrievals as follows. First, a limb observation is simulated assuming a water vapor profile according to the US Standard model atmosphere, surface albedo of 0.5 , and surface elevation of $2.2 \mathrm{~km}$. The latter corresponds to an observation above the NOAA Earth System Research Laboratory in Boulder, CO, USA. The simulations are performed for a solar zenith angle of $64^{\circ}$. This synthetic limb observation is used then to perform a series of retrievals using various assumptions about the tropospheric water vapor amount and surface properties. As shown in Fig. 10, synthetic retrievals 

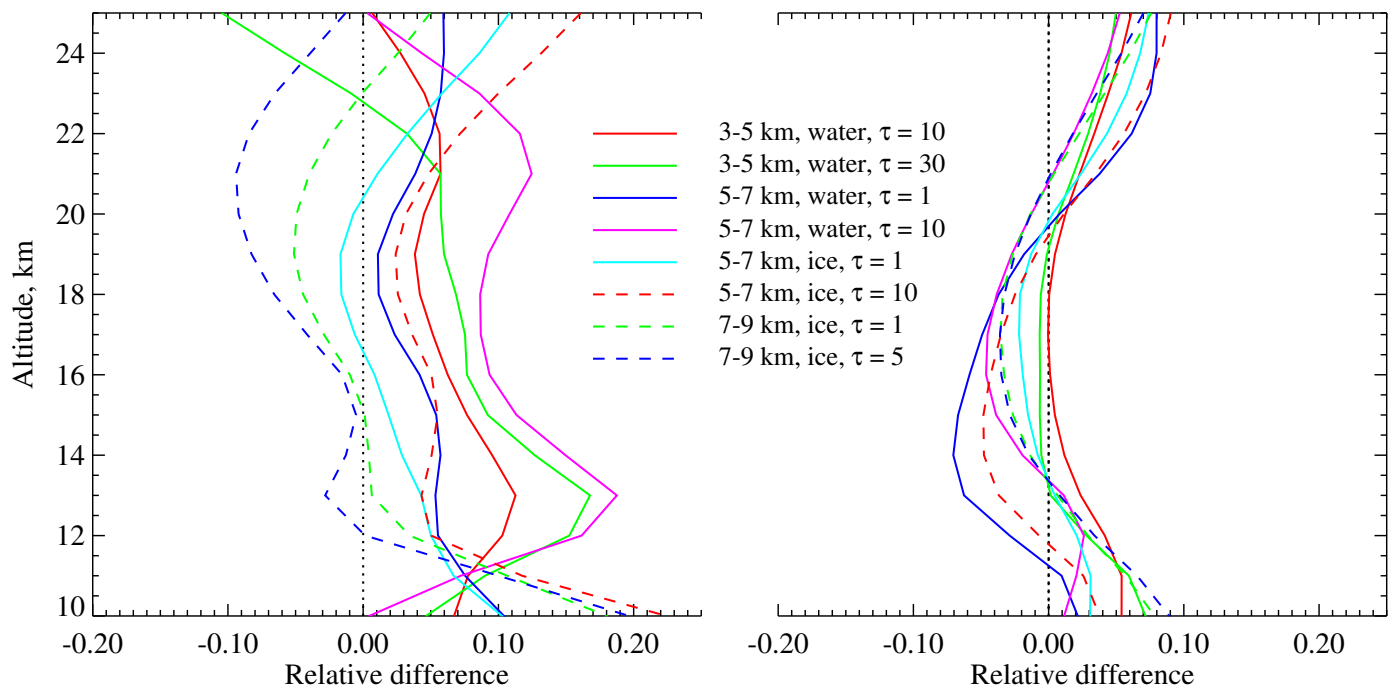

Fig. 11. Relative retrieval errors due to clouds for a tropical (left panel) and a high-latitude measurement (right panel) for water and ice clouds at different altitudes for different cloud optical thicknesses $(\tau)$.

are performed using surface albedos of 0 and 1 (red and magenta solid lines, respectively), doubling and halving the tropospheric water vapor amount at different surface albedos (green, blue, light blue solid lines and green dashed line) and raising the surface to $6 \mathrm{~km}$ (red dashed line). Results of the complete retrieval including the weighting functions for the tropospheric contribution and surface albedo (as described in Sect. 3.3) are shown in the right panel. For a comparison, the left panel of the figure illustrates the errors of the basic retrieval where only stratospheric water vapor amounts are fitted and contributions of the tropospheric water vapor and of the surface properties are neglected. The left panel of the plot reveals that changes in atmospheric or surface parameters which decrease the amount of light traveled long paths through the lower atmosphere (e.g., decrease in the surface albedo, or doubling of tropospheric water vapor amount) affect the retrieval only weakly. On the contrary, the scenarios where more light from the lower troposphere reaches the detectors (e.g., increase in the surface albedo, higher surface elevation, or halved amount of the tropospheric water vapor) cause dramatic changes in the retrieved profiles. However, as shown in the right panel of Fig. 10, these effects are almost completely accounted for if the weighting functions for the tropospheric contribution and for the surface albedo are included in the retrieval.

\subsection{Treatment of clouds}

As mentioned in Sect. 3.3, limb scans for which a high cloud (cloud top height above $10 \mathrm{~km}$ ) is detected in the instrument field of view are rejected from the further consideration. The cloud detection is done using the SCODA algorithm in a manner similar to Kokhanovsky et al. (2005); von Savigny et al. (2005). The main idea of this method is to analyze the so-called color ratio index. For a tangent height $h_{i}$ it is written as

$\Theta\left(h_{i}\right)=\frac{I\left(\lambda_{1}, h_{i}\right)}{I\left(\lambda_{2}, h_{i}\right)} \frac{I\left(\lambda_{2}, h_{i+1}\right)}{I\left(\lambda_{1}, h_{i+1}\right)}$,

where $I(\lambda, h)$ is the measured limb radiance integrated around wavelengths $\lambda_{1}$ and $\lambda_{2}$. A cloud is detected if the color ratio index exceeds a threshold value. In this study three wavelength pairs are used to create color indexes, namely $(750 \mathrm{~nm}, 1090 \mathrm{~nm}),(1090 \mathrm{~nm}, 1552 \mathrm{~nm})$ and $(1552 \mathrm{~nm}, 1685 \mathrm{~nm})$. A measurement is filtered out if one of the indexes detects a high cloud.

In contrast to high clouds, clouds below the instrument field of view do not affect the retrieval much and, thus, corresponding measurements are not excluded. The retrieval error due to the clouds below the instrument field of view is analyzed using the synthetic retrievals as follows. First, the synthetic limb radiance in a presence of a cloud is calculated. This synthetic radiance is used then as the input for the retrieval algorithm which is run assuming a cloud free atmosphere. Results for water and ice clouds at different altitudes are presented in Fig. 11. The left panel shows an observation geometry typical for the tropics (solar zenith angle of about $40^{\circ}$, scattering angle close to $90^{\circ}$ ). Here, water clouds with higher optical thickness $(\tau)$ and high ice clouds affect the retrieval results somewhat stronger. The overall effect is rather small and the relative differences remain typically below $15 \%$. Similar results but for an observation geometry typical for high latitudes of the Northern Hemisphere (solar zenith angle of about $85^{\circ}$, scattering angle of about $40^{\circ}$ ) are shown in the right panel of Fig. 11. Here, the effect is even smaller than for the tropics for all types of clouds. The retrieval error never exceeds $10 \%$. The variation of the relative retrieval error along the SCIAMACHY orbit (i.e. with the 


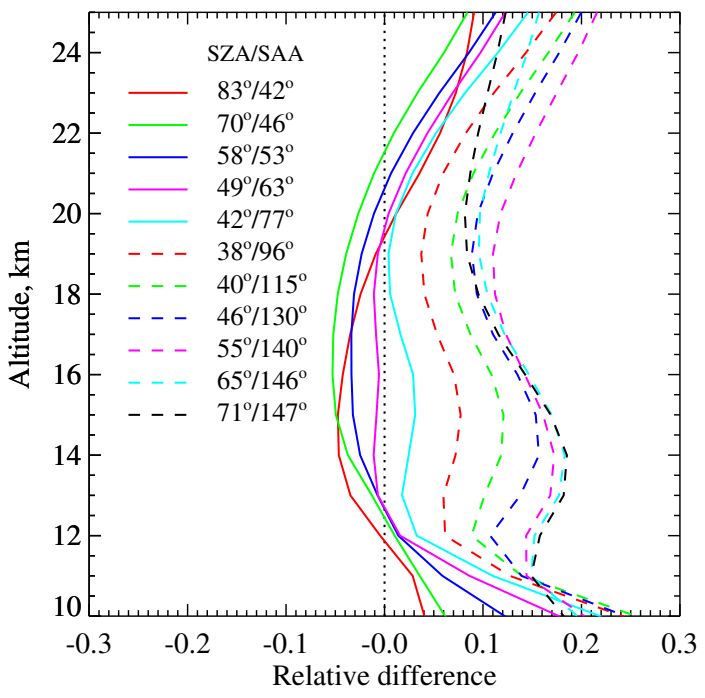

Fig. 12. Relative retrieval errors due to clouds for different observation geometries (along SCIAMACHY orbit). The legend indicates the solar zenith angle (SZA) and relative azimuth angle (SAA) at a tangent point for each observation. Simulations are done for an ice cloud between 5 and $7 \mathrm{~km}$ with an optical thicknesses of 10 .

observation geometry) for one particular cloud type is shown in Fig. 12. Here, the simulations are performed for an ice cloud between 5 and $7 \mathrm{~km}$ with an optical thicknesses of 10 . Although the retrieval errors still remain within $20 \%$ for all observations, one sees a clear increase in relative deviations when moving form small to large scattering angles (i.e. from the Northern to the Southern Hemisphere).

\subsection{Stratospheric aerosols}

In this section, the influence of stratospheric aerosols upon the retrieved vertical profiles of water vapor is considered. This is done using synthetic retrievals in a similar manner as discussed above for clouds. The synthetic radiances are simulated assuming different stratospheric aerosol scenarios according to the LOWTRAN parameterization (Kneizys et al., 1986). Each scenario is defined by stratospheric aerosol loading (background, moderate volcanic, and high volcanic) and aerosol type (background, aged volcanic, fresh volcanic). The aerosol extinction coefficients at $1352 \mathrm{~nm}$ for different scenarios are shown in Fig. 13. It is worth noting here that aerosol extinction profiles observed after the Kasatochi volcanic eruption in September 2008 peak at about $17-18 \mathrm{~km}$ altitude with maximum values of about $0.003-0.004 \mathrm{~km}^{-1}$, e.g., (Sioris et al., 2010a), which is somewhere between the solid cyan and dashed red curves in the plot.

The retrieval algorithm is initialized with the aerosol extinction coefficient profile obtained by fitting simulated radiance profiles at 1090 and $1552 \mathrm{~nm}$ ("non-absorbing" wavelengths). The retrieval is performed then including the scaling factor for the aerosol extinction profile as discussed in

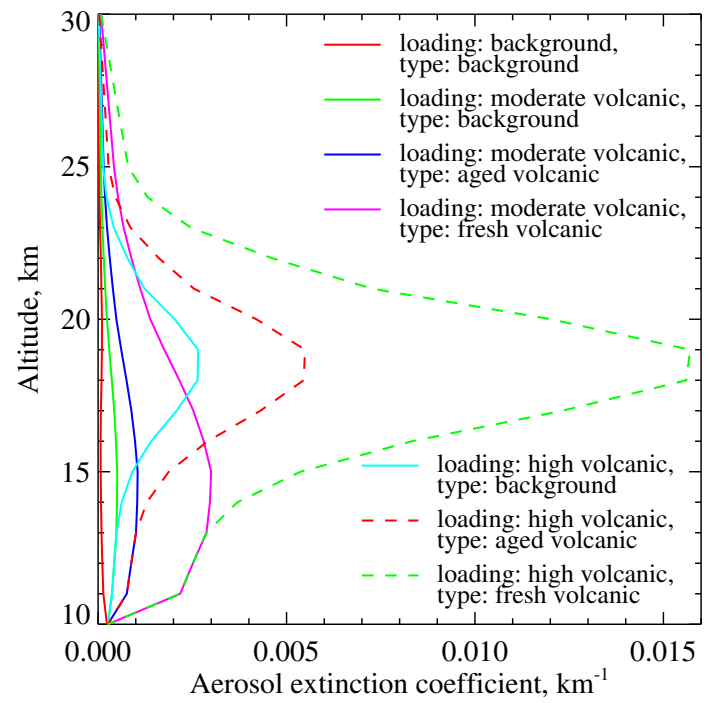

Fig. 13. Aerosol extinction profiles at $1352 \mathrm{~nm}$ for different LOWTRAN scenarios.

Sect. 3.3. For a comparison, a similar investigation is performed neglecting the aerosol correction. In this case, the retrieval is initialized with a background aerosol loading according to the LOWTRAN parameterization and no scaling of the aerosol extinction coefficient is performed.

Figure 14 shows the results for a tropical scenario which is characterized by small solar zenith angles (typically about $40^{\circ}$ ) and scattering angles of about $90^{\circ}$. The left panel of the plot illustrates the impact of the stratospheric aerosol upon the retrieved water vapor profiles if no aerosol correction is applied. If the aerosol loading is not too high the relative retrieval error remains below $30 \%$ down to $14-16 \mathrm{~km}$ depending on the scenario. Otherwise, larger retrieval errors might occur. The right panel shows the retrieval results if the stratospheric aerosol correction is applied. Here, the errors are substantially smaller remaining below $15 \%$ in the entire altitude range for all aerosol scenarios except for high loading with fresh volcanic aerosol.

Similar results for an observation geometry typical for high-latitude winter season in the Northern Hemisphere are presented in Fig. 15. This scenario is characterized by large solar zenith angles $\left(80-85^{\circ}\right)$ and high contribution of the forward scattering by aerosols into the measured signal (scattering angle of about $40^{\circ}$ ). While for most of the aerosol scenarios the retrieval errors are nearly the same as for tropics (both corrected and non-corrected retrievals), substantially higher errors are observed for the aerosol corrected retrieval in the case of a high loading with fresh volcanic aerosol.

In conclusion, the influence of the stratospheric aerosols upon the retrieved water vapor profiles is estimated to be about $10-15 \%$ for aerosol loading situations observed in the years from 2002 to 2011. As a stratospheric pollution that would be strong enough to cause substantial retrieval errors 

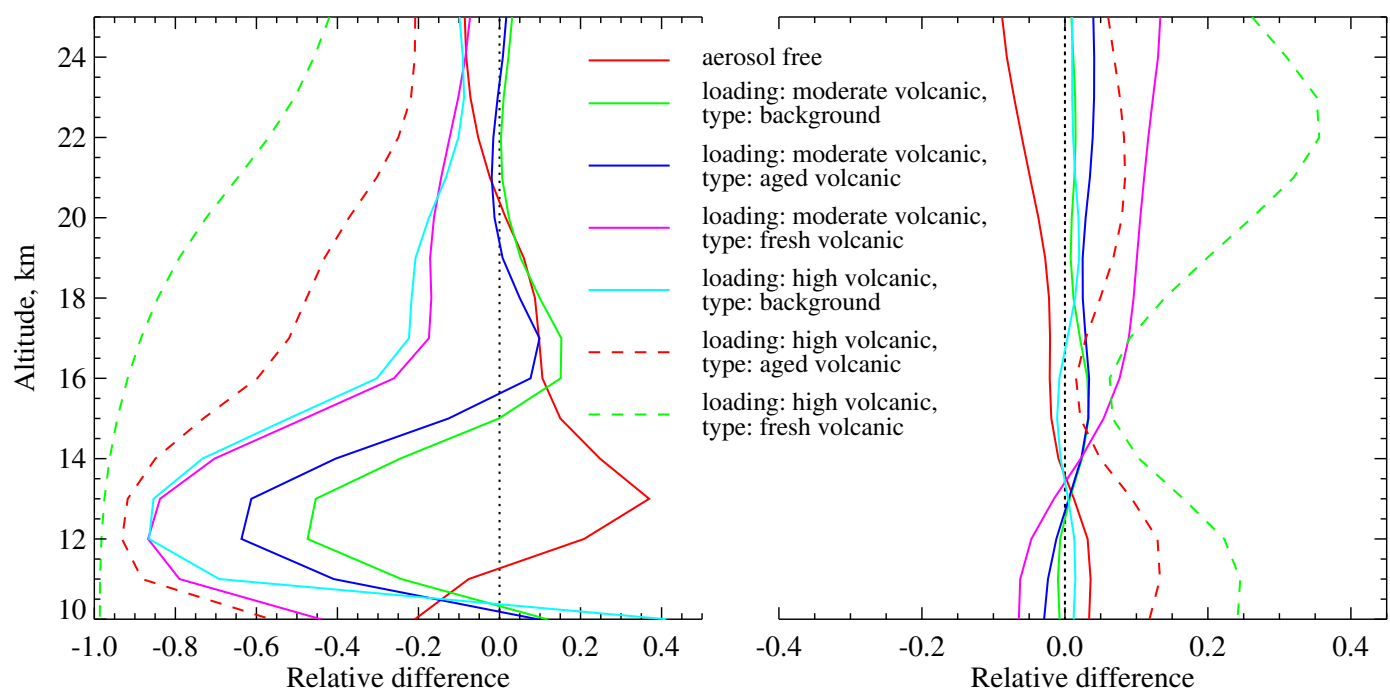

Fig. 14. Relative retrieval errors due to stratospheric aerosol for a tropical measurement with (right panel) and without (left panel) stratospheric aerosol correction.

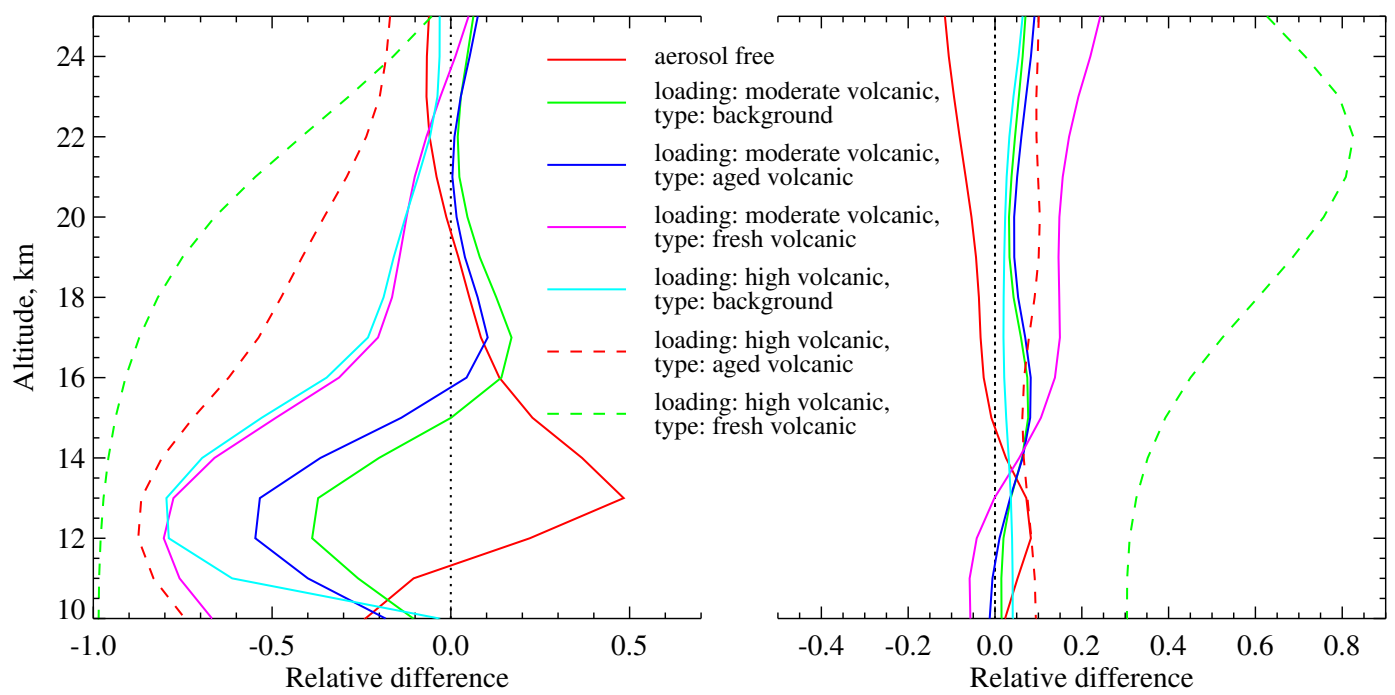

Fig. 15. Same as Fig. 14 but for an observation at high latitudes of the Northern Hemisphere.

has never been observed during the operational period of SCIAMACHY there is no need to be concerned about the quality of the existing dataset. However, in a case of a very strong volcanic eruption the affected measurements need to be filtered out. This can be done using the color ratio index similar to the cloud detection procedure. Figure 16 illustrates the detection of high aerosol loading using the 1090 to $1552 \mathrm{~nm}$ color index (see Eq. 25). As above, the results are presented for a tropical (left panel) measurement and for an observation at high-latitudes of the Northern Hemisphere in winter season (right panel).

\section{Comparisons}

In previous sections we have analyzed the retrieval precision and investigated the influence of key atmospheric parameters upon the retrieved water vapor profiles. However, there is still not enough information to assess the total error budget theoretically. Instead, in this section we estimate the total uncertainty of SCIAMACHY water vapor retrievals by comparisons with independent measurements.

To estimate the quality of single retrievals, example water vapor profiles obtained from SCIAMACHY limb observations are compared to in situ measurements performed with a balloon-borne frost point hygrometer (FPH) over Boulder, CO, USA (data provided by NOAA Earth System Research 


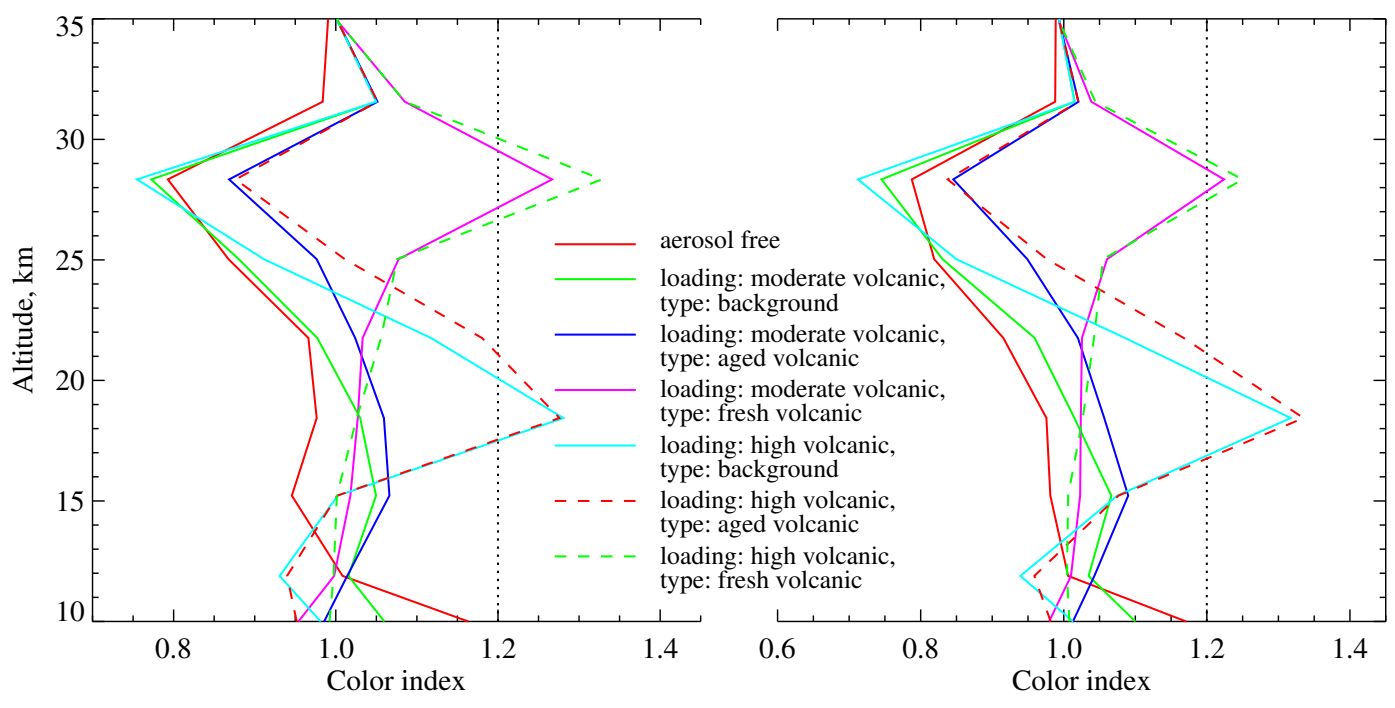

Fig. 16. Color index (1090 to $1552 \mathrm{~nm})$ for different aerosol scenarios. Left panel: a typical tropical measurement. Right panel: an observation geometry typical for winter season at high-latitudes of the Northern Hemisphere. Dashed lines show the cloud detection threshold that is currently used in the SCODA algorithm.
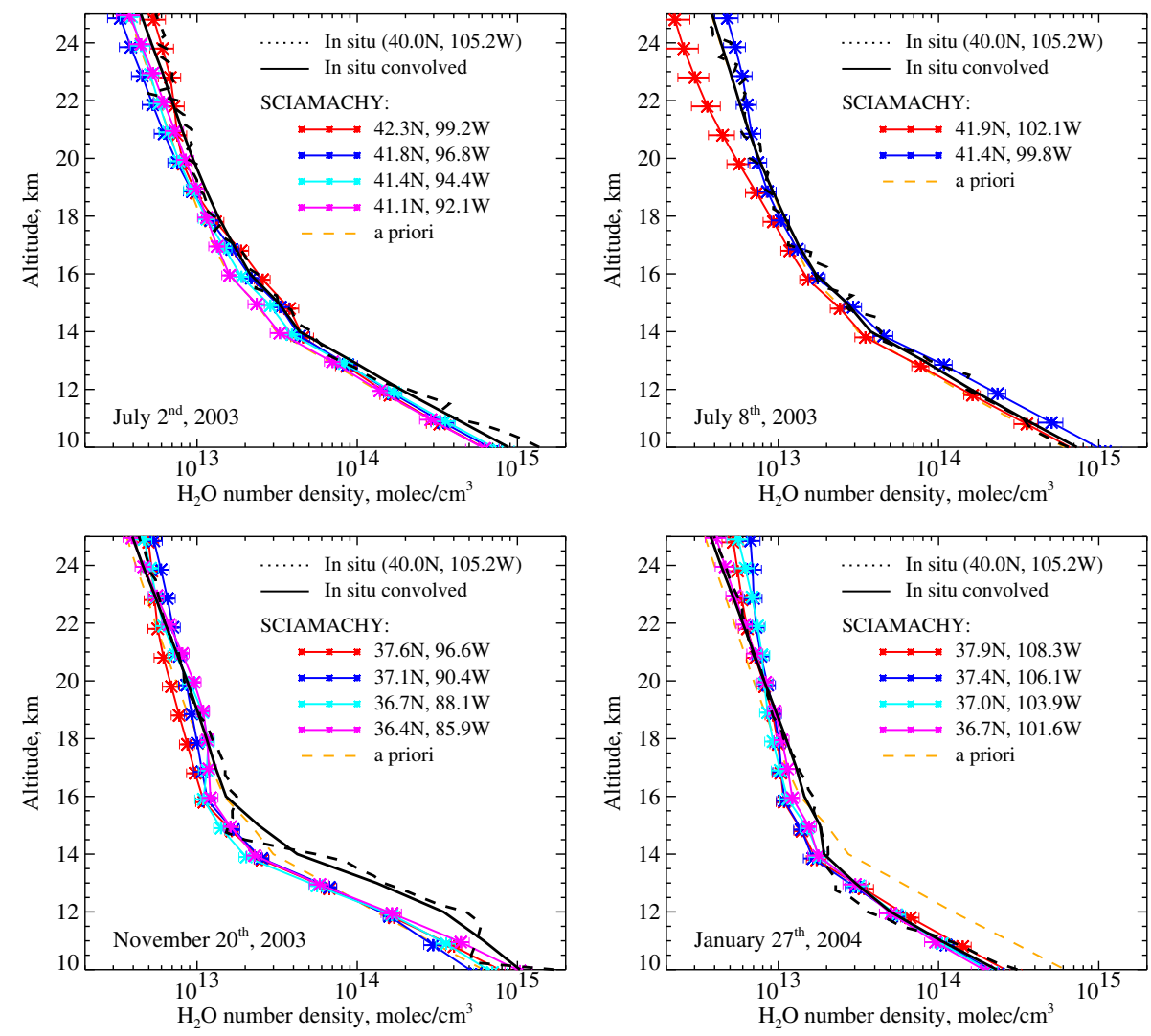

Fig. 17. Comparison to in situ measurements performed with a balloon-borne frost point hygrometer (FPH) over Boulder, CO, USA for four selected balloon launches. Original water vapor profiles obtained from the frost point hygrometer are shown with black dashed lines whereas black solid lines show the same profiles but convolved with SCIAMACHY averaging kernels. Color solid lines depict water vapor profiles retrieved from SCIAMACHY limb observations (up to four profiles per limb observation due to an azimuthal scan) and the dashed orange line shows the a priori water vapor profile used for SCIAMACHY retrievals. 

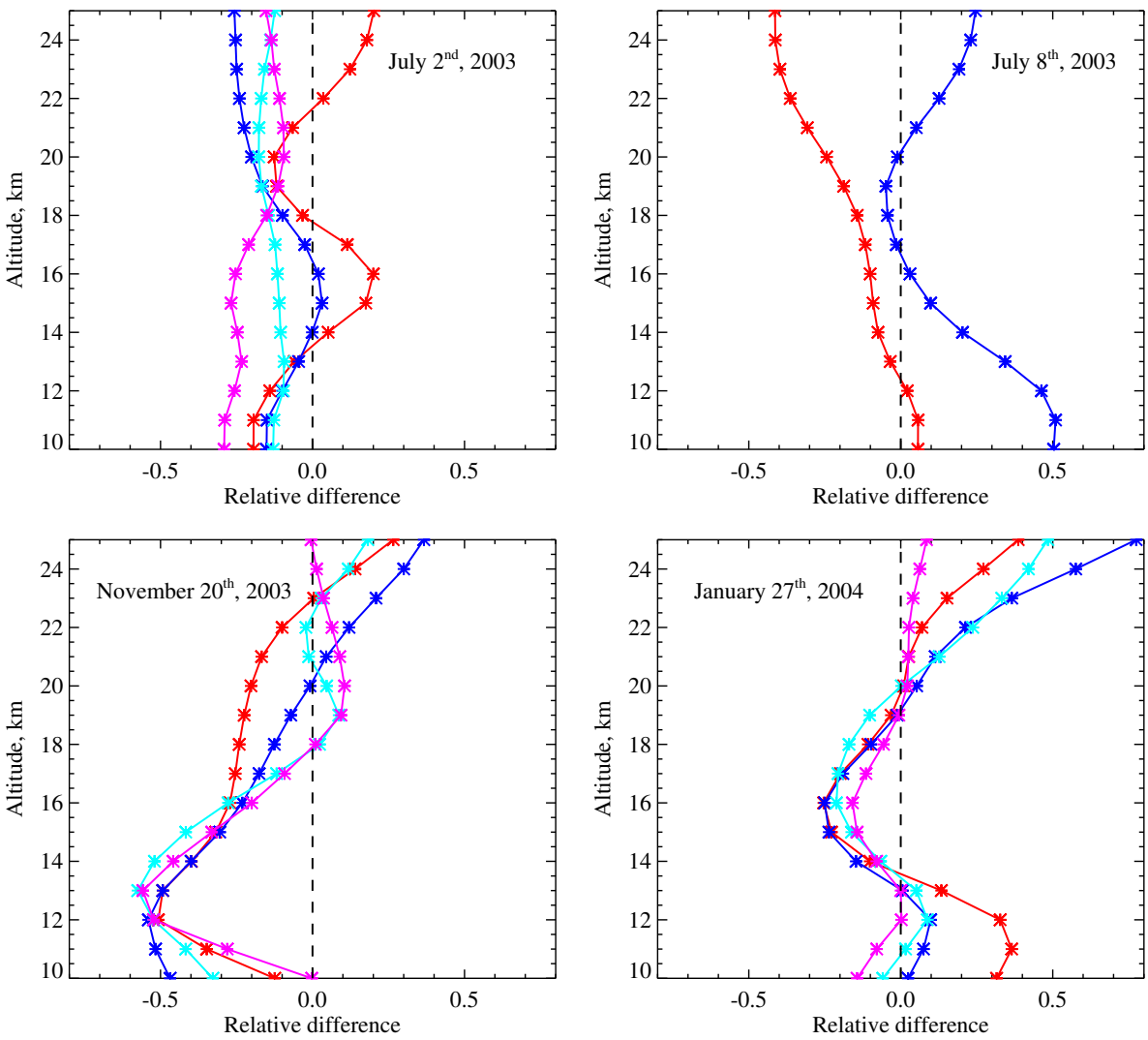

Fig. 18. Same as Fig. 17 but for relative differences.

Laboratory, Global Monitoring Division). The uncertainty of balloon-borne FPH measurements is estimated to be about $10 \%$. Further details on the instrument are presented in Vömel et al. (1995). Water vapor profiles are compared for four balloon flights performed on 2 July 2003, 8 July 2003, 20 November 2003, and 27 January 2004. Collocations are selected according to the best match principle requiring the time difference between two measurements to be within $12 \mathrm{~h}$.

Results of the comparison are presented in Figs. 17 (for profiles) and 18 (for relative differences with respect to in situ measurements). Water vapor profiles obtained from the balloon-borne instrument are shown with dashed black lines for original profiles and with solid black lines for profiles convolved with SCIAMACHY averaging kernels. The SCIAMACHY retrievals are shown by solid lines with asterisks and corresponding a priori profiles are depicted by dashed orange lines. As discussed in Sect. 2, during each limb measurement sequence the SCIAMACHY instrument performs a horizontal across-track scan. This provides typically four independent observations per limb scan which are performed at slightly different azimuthal angles. The water vapor profiles obtained from these azimuthal measurements are shown with different colors. As measurements contaminated by high clouds are filtered out, for some limb observations less than four profiles are retrieved (e.g., upper right panel in Figs. 17 and 18).
The comparison demonstrates stability of single SCIAMACHY retrievals and shows good overall agreement between the SCIAMACHY and balloon profiles with relative differences being typically below $30 \%$.

A more extensive verification of SCIAMACHY retrievals is performed using in situ measurements with a balloonborne cryogenic frost point hygrometer $(\mathrm{CFH})$ operated at different locations. In this study the data obtained at the following balloon launch sites are considered: Boulder, $\mathrm{CO}$, USA $\left(40^{\circ} \mathrm{N}, 105^{\circ} \mathrm{W}\right)$; Heredia, Costa Rica $\left(10^{\circ} \mathrm{N}, 84^{\circ} \mathrm{W}\right)$, Beltsville, MD, USA $\left(39^{\circ} \mathrm{N}, 77^{\circ} \mathrm{W}\right)$; Sodankylä, Finland $\left(67^{\circ} \mathrm{N}, 27^{\circ} \mathrm{E}\right)$; Kototabang, Indonesia $\left(0.2^{\circ} \mathrm{S}, 100^{\circ} \mathrm{E}\right)$; Ha Noi, Vietnam $\left(21^{\circ} \mathrm{N}, 106^{\circ} \mathrm{E}\right)$; Alajuela, Costa Rica $\left(10^{\circ} \mathrm{N}\right.$, $\left.84^{\circ} \mathrm{W}\right)$; Lindenberg, Germany $\left(52^{\circ} \mathrm{N}, 14^{\circ} \mathrm{E}\right)$. The in situ observations have been performed in the period between November 2004 and November 2008. The uncertainty of balloon-borne CFH measurements is estimated to be about $10 \%$. Details on the instrument and measurement campaigns can be found in Vömel et al. (2007b); Fujiwara et al. (2010); Selkirk et al. (2010). A map showing locations of the balloon launch sites and tangent points of coinciding SCIAMACHY measurements is presented in Fig. 19. The SCIAMACHY measurements are selected requiring a maximum distance of $1000 \mathrm{~km}$ and maximum time mismatch of $5 \mathrm{~h}$ (with respect to the balloon launch time). For each balloon flight several coinciding SCIAMACHY measurements might exist. 


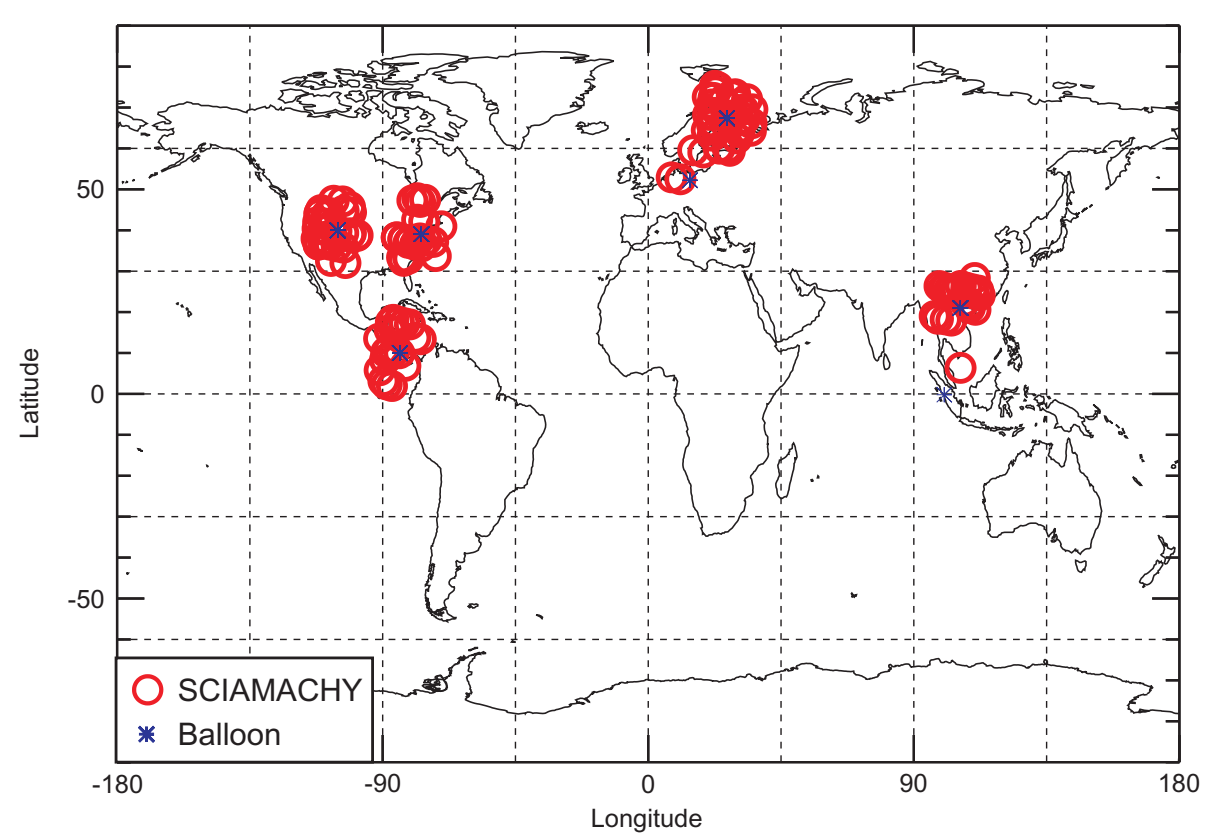

Fig. 19. Locations of balloon launch sites considered in this study and tangent points of coinciding SCIAMACHY observations.
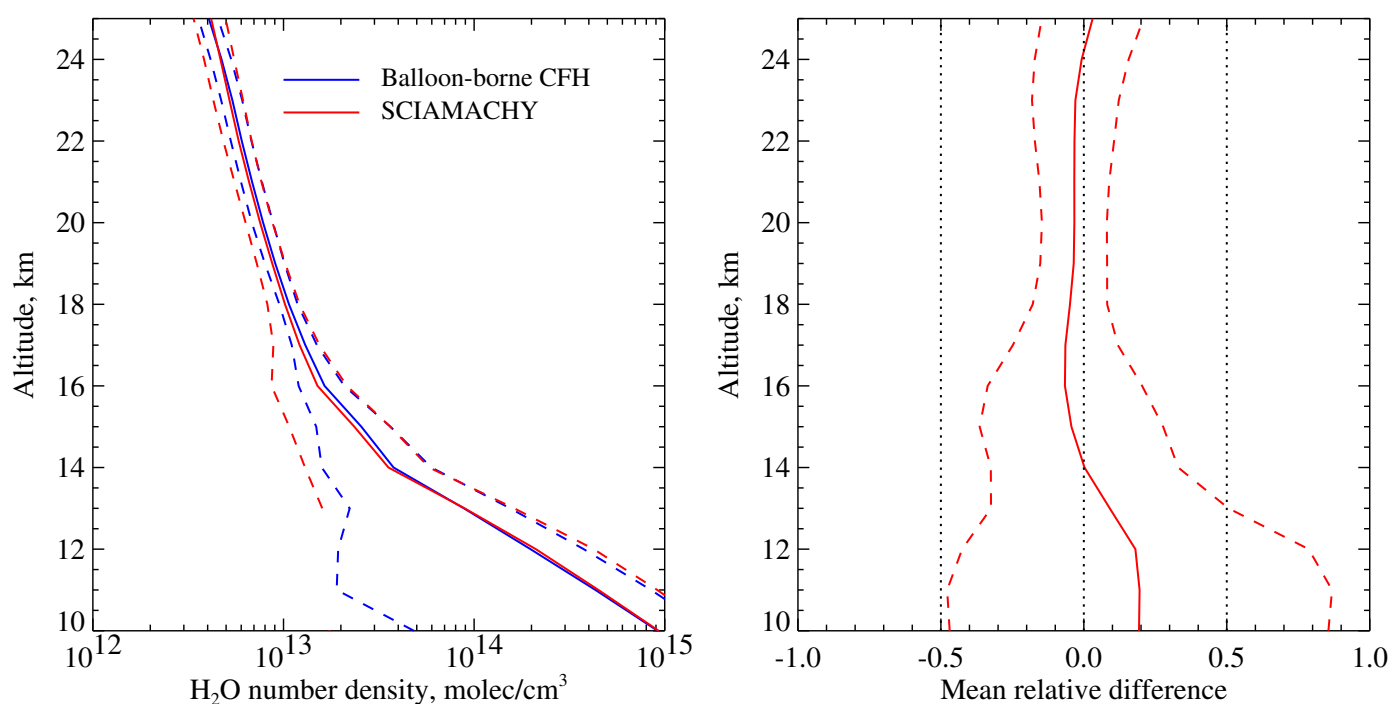

Fig. 20. Comparison to in situ balloon-borne observations. Left panel: solid lines show balloon-borne CFH (blue) and SCIAMACHY (red) profiles averaged over all balloon launches at all locations as shown in Fig. 19 whereas dashed lines depict corresponding standard deviations. Right panel: mean relative difference between SCIAMACHY and balloon-borne CFH results (solid line) and corresponding standard deviation (dashed lines).

In all comparisons below water vapor profiles obtained from balloon-borne instrument are convolved with SCIAMACHY averaging kernels.

Figure 20 presents a comparison of water vapor profiles obtained from balloon-borne CFH and SCIAMACHY measurements. The results are averaged over all balloon launches at all sites as shown in Fig. 19. In total 140 SCIAMACHY observations and 48 balloon flights are considered. The left panel of the plot shows average balloon-borne CFH (blue) and SCIAMACHY (red) profiles with solid lines and corresponding standard deviations with dashed lines. The right panel shows the mean relative difference between both measurements (SCIAMACHY/CFH-1) and corresponding standard deviation. The plot reveals good overall agreement between the two datasets. The results agree within $10 \%$ above $13 \mathrm{~km}$ and differ somewhat more below. 

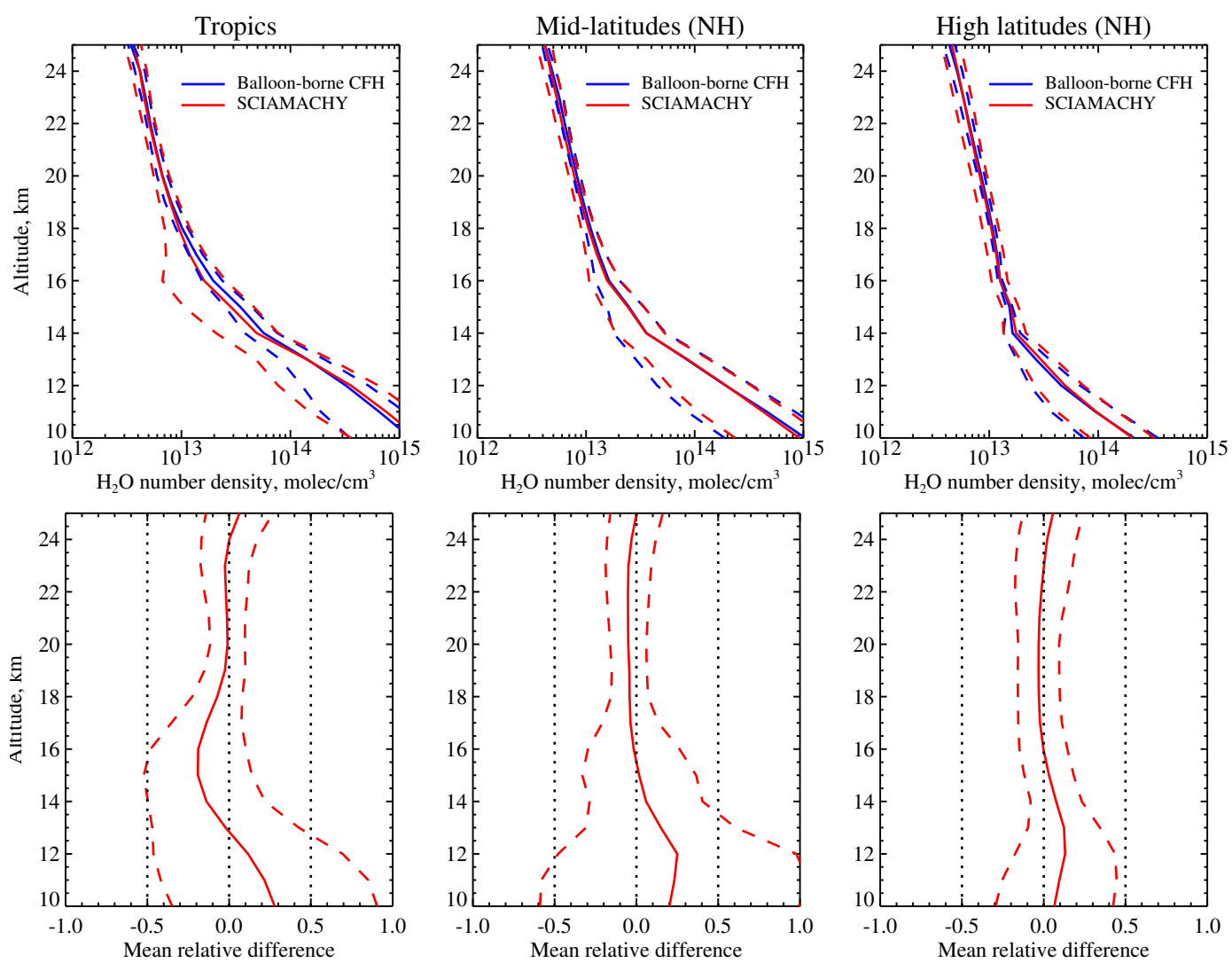

Fig. 21. Comparison to in situ balloon-borne observations for different latitudinal ranges: tropics (left), mid-latitudes of the Northern Hemisphere (middle), and high latitudes of the Northern Hemisphere (right). Upper panels show average balloon-borne CFH (blue) and SCIAMACHY (red) profiles with solid lines and corresponding standard deviations with dashed lines. Lower panels show mean relative differences between SCIAMACHY and balloon-borne CFH results (solid line) and corresponding standard deviations (dashed lines).

A similar comparison but for water vapor profiles averaged within certain zonal bands is presented in Fig. 21. Here, the same notations as in Fig. 20 are used. Upper panels show the averaged profiles from both instruments and their standard deviations, whereas lower panels show mean relative differences and corresponding standard deviations. The left panels show a comparison for the tropics $\left(30^{\circ} \mathrm{S}-30^{\circ} \mathrm{N}\right)$ where results from 43 SCIAMACHY measurements and 13 balloon launches are considered. In this region the results from both instruments agree within $10 \%$ down to $17 \mathrm{~km}$ and within $20 \%$ below. Below $17 \mathrm{~km}$ an increase in standard deviations both for profiles and for relative errors is observed. The main reason is most probably that in the tropics these altitudes are located in the troposphere with an inherent high variability of water vapor content. A similar behavior has been observed in the comparison of CFH and Aura MLS results presented in Vömel et al. (2007a). The middle panels of Fig. 21 present comparison results for middle latitudes of the Northern Hemisphere $\left(30^{\circ} \mathrm{N}-60^{\circ} \mathrm{N}\right)$ considering results from 64 SCIAMACHY measurements and 21 balloon launches. Here, an agreement within $10 \%$ is observed down to $14 \mathrm{~km}$ with a slight increase in relative difference below.
In the right panels a similar comparison for high latitudes of the Northern Hemisphere (above $60^{\circ} \mathrm{N}$ ) is presented. Here, 33 SCIAMACHY measurements and 15 balloon launches are considered. Down to $14 \mathrm{~km}$ both datasets agree within $5 \%$ and differ by $10-15 \%$ below.

\section{Conclusions}

In contrast to space-borne observations of the emitted radiance or transmitted solar light which have been widely exploited previously, measurements of scattered solar light performed by SCIAMACHY in limb viewing geometry provide a completely new source of information on vertical distribution of water vapor in the lower stratosphere and upper troposphere (UTLS) altitude region. In this study we suggest a new method capable to retrieve UTLS water vapor contents from this kind of measurements. The paper describes an optimal selection of the spectral range and analyses contributions of different processes (multiple scattering, surface albedo, aerosols) into the measured spectral signal. The applied retrieval algorithm is described in detail and sensitivity 
of retrievals is investigated. The highest sensitivity is found to be between 11 and $23 \mathrm{~km}$. By means of synthetic retrievals, the performance of the algorithm and its weak sensitivity to major atmospheric and surface parameters other than UTLS water vapor content is demonstrated.

The new method is successfully applied to SCIAMACHY limb observations. A verification of the retrieval results is performed using data from in situ balloon-borne measurements with frost point or cryogenic frost point hygrometers. The comparison reveals an overall good agreement between the SCIAMACHY and balloon instruments in the relevant altitude range. The datasets are found to agree typically within $10 \%$. An extensive validation of UTLS water vapor profiles retrieved from SCIAMACHY limb measurements is ongoing.

Acknowledgements. We thank Sam Oltmans and Dale F. Hurst (NOAA Earth System Research Laboratory, Global Monitoring Division) for providing NOAA FPH profile data. The $\mathrm{CFH}$ measurements from Beltsville, MD were made at the Howard University Beltsville Campus during the WAVES field campaigns supported by the NASA Atmospheric Chemistry Program and led by David Whiteman of NASA/GSFC, Everette Joseph and Belay Demoz of Howard University. The CFH measurements at Biak, Kototabang, and Ha Noi were made under the Soundings of Ozone and Water in the Equatorial Region (SOWER) project led by Fumio Hasebe (Hokkaido University), Masato Shiotani (Kyoto University), and Masatomo Fujiwara (Hokkaido University). We are thankful to ECMWF for providing pressure and temperature information (ECMWF Special Project SPDECDIO). Some data shown here were calculated on German HLRN (High-Performance Computer Center North) and NIC/JUMP (Forschungszentrum Jülich Multiprocessor System). Services and support are gratefully acknowledged. This study has been funded by DLR Space Agency (Germany), grant 50EE0727, European Commission EC SCOUTO3, and by the University and State of Bremen. Part of this work has been supported by the DFG Research Unit FOR 1095 "Stratospheric Change and its role for Climate Prediction (SHARP)" (Project: GZ WE 3647/3-1).

Edited by: E. Kyrölä

\section{References}

Argall, P. S., Sica, R., Bryant, C., Algara-Siller, M., and Schijns, H.: Calibration of the Purple Crow Lidar Raman water vapour and temperature measurements, Can. J. Phys., 85, 119-129, 2007.

Backus, G. E. and Gilbert, F. E.: Uniqueness in the inversion of inaccurate gross Earth data, Philos. T. Roy. Soc. Lond. A, 266, 123-192, 1970.

Boone, C. D., Nassar, R., Walker, K. A., Rochon, Y., McLeod, S. D., Rinsland, C. P., and Bernath, P. F.: Retrievals for the atmospheric chemistry experiment Fourier-transform spectrometer, Appl. Optics, 44, 7218-7231, 2005.

Bovensmann, H., Burrows, J. P., Buchwitz, M., Frerick, J., Noël, S., Rozanov, V. V., Chance, K. V., and Goede, A. P. H.: SCIAMACHY: Mission objectives and measurement modes, J. Atmos. Sci., 56, 127-149, 1999.
Buchwitz, M., Rozanov, V. V., and Burrows, J. P.: A correlated-k distribution scheme for overlapping gases suitable for retrieval of atmospheric constituents from moderate resolution radiance measurements in the visible/near-infrared spectral region, J. Geophys. Res., 105, 15247-15261, 2000.

Burrows, J. P., Hölzle, E., Goede, A. P. H., Visser, H., and Fricke, W.: SCIAMACHY - Scanning Imaging Absorption Spectrometer for Atmospheric Chartography, Acta Astronaut., 35, 445451, 1995.

Committee on Extension to the Standard Atmosphere: U.S. Standard Atmosphere, 1976, Government Printing Office, Washington, D.C., 1976.

de F. Forster, P. M. and Shine, K. P.: Stratospheric water vapour changes as a possible contributor to observed stratospheric cooling, Geophys. Res. Lett., 26, 3309-3312, doi:10.1029/1999GL010487, 1999.

Deuber, B., Kämpfer, N., and Feist, D. G.: A new 22$\mathrm{GHz}$ Radiometer for Middle Atmospheric Water Vapour Profile Measurements, IEEE T. Geosci. Remote, 42, 974-984, doi:10.1109/TGRS.2004.825581, 2004.

Dhomse, S., Weber, M., and Burrows, J.: The relationship between tropospheric wave forcing and tropical lower stratospheric water vapor, Atmos. Chem. Phys., 8, 471-480, doi:10.5194/acp-8-4712008, 2008.

Friedl-Vallon, F., Maucher, G., Kleinert, A., Lengel, A., Keim, C., Oelhaf, H., Fischer, H., Seefeldner, M., and Trieschmann, O. Design and characterisation of the ballonborne Michelson Interferometer for Passive Atmospheric Sounding (MIPAS B2), Appl. Optics, 43, 3335-3355, 2004.

Fujiwara, M., Voemel, H., Hasebe, F., Shiotani, M., Ogino, S.Y., Iwasaki, S., Nishi, N., Shibata, T., Shimizu, K., Nishimoto, E., Valverde-Canossa, J. M., Selkirk, H. B., and Oltmans, S. J.: Seasonal to decadal variations of water vapor in the tropical lower stratosphere observed with balloon-borne cryogenic frost point hygrometers, J. Geophys. Res., 115, D18304, doi:10.1029/2010JD014179, 2010.

Hagan, D. E., Webster, C. R., Farmer, C. B., May, R. D., Herman, R. L., Weinstock, E. M., Christensen, L. E., Lait, L. R., and Newman, P. A.: Validating AIRS upper atmosphere water vapor retrievals using aircraft and balloon in situ measurements, Geophys. Res. Lett., 31, L21103, doi:10.1029/2004GL020302, 2004.

Haley, C. S., Brohede, S. M., Sioris, C. E., Griffioen, E., Murtagh, D. P., McDade, I. C., Eriksson, P., Llewellyn, E. J., Bazureau, A., and Goutail, F.: Retrieval of stratospheric $\mathrm{O}_{3}$ and $\mathrm{NO}_{2}$ profiles from Odin Optical Spectrograph and Infrared Imager System (OSIRIS) limb-scattered sunlight measurements, J. Geophys. Res., 109, D16303, doi:10.1029/2004JD004588, 2004.

Harries, J. E., Russell III, J. M., Tuck, A. F., Gordley, L. L., Purcell, P., Stone, K., Bevilacqua, R. M., Gunson, M., Nedoluha, G., and Traub, W. A.: Validation of measurements of water vapor from the halogen occultation experiment (HALOE), J. Geophys. Res., 101, 10205-10216, 1996.

Harwood, R., Carr, E., Froidevaux, L., Jarnot, R., Lahoz, W., Lau, C., Peckham, G., Read, W., Ricaud, P., Suttie, R., and Waters, J.: Springtime stratospheric water vapour in the southern hemisphere as measured by MLS, Geophys. Res. Lett., 20, 12351238, 1993.

Hoogen, R., Rozanov, V. V., and Burrows, J. P.: Ozone profiles from 
GOME satellite data: Algorithm description and first validation, J. Geophys. Res., 104, 8263-8280, doi:10.1029/1998JD100093, 1999.

Kiemle, C., Wirth, M., Fix, A., Ehret, G., Schumann, U., Gardiner, T., Schiller, C., Sitnikov, N., and Stiller, G.: First airborne water vapor lidar measurements in the tropical upper troposphere and mid-latitudes lower stratosphere: accuracy evaluation and intercomparisons with other instruments, Atmos. Chem. Phys., 8, 5245-5261, doi:10.5194/acp-8-5245-2008, 2008.

Kikuchi, K., Nishibori, T., Ochiai, S., Ozeki, H., Irimajiri, Y., Kasai, Y., Koike, M., Manabe, T., Mizukoshi, K., Murayama, Y., Nagahama, T., Sano, T., Sato, R., Seta, M., Takahashi, C., Takayanagi, M., Masuko, H., Inatani, J., Suzuki, M., and Shiotani, M.: Overview and Early Results of the Superconducting Submillimeter-Wave Limb-Emission Sounder (SMILES), J. Geophys. Res., 115, D23306, doi:10.1029/2010JD014379, 2010.

Klenk, K. F., Bhartia, P. K., Kaveeshwar, V. G., McPeters, R. D., Smith, P. M., and Fleig, A. J.: Total Ozone Determination from the Backscattered Ultraviolet (BUV)Total Ozone Determination from the Backscattered Ultraviolet (BUV) Experiment Experiment, J. Appl. Meteorol., 21, 1672-1684, 1982.

Kneizys, F. X., Shettle, E. P., Abreu, L. W., Chetwynd, J. H., Anderson, G. P., Gallery, W. O., Selby, J. E. A., and Clough, S. A.: Users Guide to LOWTRAN 7, Tech. rep., Air Force Geophysics Laboratory AFGL, 1986.

Kokhanovsky, A. A., Rozanov, V. V., Burrows, J. P., Eichmann, K.-U., Lotz, W., and Vountas, M.: The SCIAMACHY cloud products: Algorithms and examples from ENVISAT, Adv. Space Res., 36, 789-799, doi:10.1016/j.asr.2005.03.026, 2005.

Krecl, P., Haley, C. S., Stegman, J., Brohede, S. M., and Berthet, G.: Retrieving the vertical distribution of stratospheric OClO from Odin/OSIRIS limb-scattered sunlight measurements, Atmos. Chem. Phys., 6, 1879-1894, doi:10.5194/acp-6-1879-2006, 2006.

Matthews, E.: Global Vegetation and Land Use: New HighResolution Data Bases for Climate Studies, J. Clim. Appl. Meteorol., 22, 474-487, 1983.

Milz, M., von Clarmann, T., Fischer, H., Glatthor, N., Grabowski, U., Höpfner, M., Kellmann, S., Kiefer, M., Linden, A., Mengistu Tsidu, G., Steck, T., Stiller, G. P., Funke, B., López-Puertas, M., and Koukouli, M. E.: Water vapor distributions measured with the Michelson Interferometer for Passive Atmospheric Sounding on board Envisat (MIPAS/Envisat), J. Geophys. Res., 110, D24307, doi:10.1029/2005JD005973, 2005.

Nakajima, H., Sugita, T., Yokota, T., Kobayashi, H., Sasano, Y., Ishigaki, T., Mogi, Y., Araki, N., Waragai, K., Kimura, N., Iwazawa, T., Kuze, A., Tanii, J., Kawasaki, H., Horikawa, M., Togami, T., and Uemura, N.: Characteristics and performance of the Improved Limb Atmospheric Spectrometer-II (ILAS-II) on board the ADEOS-II satellite, J. Geophys. Res., 111, D11S01, doi:10.1029/2005JD006334, 2006.

Nedoluha, G., Bevilacqua, R., Gomez, R., Thacker, D., Waltman, W., and Pauls, T.: Ground-based measurements of water vapor in the middle atmosphere, J. Geophys. Res., 100(D2), 2927-2939, 1995.

Noël, S., Bovensmann, H., Burrows, J. P., Frerick, J., Chance, K. V., Goede, A. H. P., and Muller, C.: The SCIAMACHY Instrument on ENVISAT-1, in: Sensors, Systems, and NextGeneration Satellites II, vol. 3498 of Proc. SPIE, 94-104, 1998.
Pan, L. L., Bowman, K. P., Shapiro, M., Randel, W. J., Gao, R. S., Campos, T., Davis, C., Schauffler, S., Ridley, B. A., Wei, J. C., and Barnet, C.: Chemical behavior of the tropopause observed during the Stratosphere-Troposphere Analyses of Regional Transport experiment, J. Geophys. Res., 112, D18110, doi:10.1029/2007JD008645, 2007.

Pougatchev, N., August, T., Calbet, X., Hultberg, T., Oduleye, O., Schlüssel, P., Stiller, B., Germain, K. St., and Bingham, G.: IASI temperature and water vapor retrievals - error assessment and validation, Atmos. Chem. Phys., 9, 6453-6458, doi:10.5194/acp9-6453-2009, 2009.

Randel, W. J., Wu, F., Voemel, H., Nedoluha, G. E., and Forster, P.: Decreases in stratospheric water vapor after 2001: links to changes in the tropical tropopause and the Brewer-Dobson circulation, J. Geophys. Res., 111, 12312, doi:10.1029/2005JD006744, 2006.

Read, W. G., Lambert, A., Bacmeister, J., Cofield, R. E., Christensen, L. E., Cuddy, D. T., Daffer, W. H., Drouin, B. J., Fetzer, E., Froidevaux, L., Fuller, R., Herman, R., Jarnot, R. F., Jiang, J. H., Jiang, Y. B., Kelly, K., Knosp, B. W., Kovalenko, L. J., Livesey, N. J., Liu, H.-C., Manney, G. L., Pickett, H. M., Pumphrey, H. C., Rosenlof, K. H., Sabounchi, X., Santee, M. L., Schwartz, M. J., Snyder, W. V., Stek, P. C., Su, H., Takacs, L. L., Thurstans, R. P., Vomel, H., Wagner, P. A., Waters, J. W., Webster, C. R., Weinstock, E. M., and Wu, D. L.: Aura Microwave Limb Sounder upper tropospheric and lower stratospheric $\mathrm{H}_{2} \mathrm{O}$ and relative humidity with respect to ice validation, J. Geophys. Res., 112, D24S35, doi:10.1029/2007JD008752, 2007.

Rodgers, C. D.: Retrieval of Atmospheric Temperature and Composition From Remote Measurements of Thermal Radiation, Rev. Geophys. Space Ge., 4, 609-624, 1976.

Rodgers, C. D.: Characterization and error analysis of profiles retrieved from remote sounding measurements, J. Geophys. Res., 95, 5587-5595, 1990.

Rodgers, C. D.: Inverse methods for atmospheric sounding: Theory and practice, World Scientific, 2000.

Rothman, L., Gordon, I., Barbe, A., Benner, D., Bernath, P., Birk, M., Boudon, V., Brown, L., Campargue, A., Champion, J.-P., Chance, K., Coudert, L., Dana, V., Devi, V., Fally, S., Flaud, J.M., Gamache, R., Goldman, A., Jacquemart, D., Kleiner, I., Lacome, N., Lafferty, W., Mandin, J.-Y., Massie, S., Mikhailenko, S., Miller, C., Moazzen-Ahmadi, N., Naumenko, O., Nikitin, A., Orphal, J., Perevalov, V., Perrin, A., Predoi-Cross, A., Rinsland, C., Rotger, M., Simeckova, M., Smith, M., Sung, K., Tashkun, S., Tennyson, J., Toth, R., Vandaele, A., and Vander Auwera, J.: The HITRAN 2008 molecular spectroscopic database, J. Quant. Spectrosc. Ra., 110, 533-572, doi:10.1016/j.jqsrt.2009.02.013, 2009.

Rozanov, A.: SCIATRAN: Radiative transfer model and retrieval software package, http://www.iup.physik.uni-bremen.de/ sciatran, last access: 15 February 2011.

Rozanov, V. V. and Kokhanovsky, A. A.: Impact of single- and multi-layered cloudiness on ozone vertical column retrievals using nadir observations of backscattered solar radiation, in: Light Scattering Reviews 3, edited by: Kokhanovsky, A. A., Springer, Berlin, 133-189, 2008.

Rozanov, V. V. and Rozanov, A. V.: Relationship between different approaches to derive weighting functions related to atmospheric remote sensing problems, J. Quant. Spectrosc. Ra., 105, 217- 
242, 2007.

Rozanov, A., Rozanov, V., and Burrows, J. P.: A numerical radiative transfer model for a spherical planetary atmosphere: combined differential-integral approach involving the Picard iterative approximation, J. Quant. Spectrosc. Ra., 69, 491-512, doi:10.1016/S0022-4073(00)00100-X, 2001.

Rozanov, A., Rozanov, V., Buchwitz, M., Kokhanovsky, A., and Burrows, J. P.: SCIATRAN 2.0 - A new radiative transfer model for geophysical applications in the $175-2400 \mathrm{~nm}$ spectral region, Adv. Space Res., 36, 1015-1019, doi:10.1016/j.asr.2005.03.012, 2005.

Selkirk, H. B., Vömel, H., Valverde Canossa, J. M., Pfister, L., Diaz, J. A., Fernández, W., Amador, J., Stolz, W., and Peng, G.: Detailed structure of the tropical upper troposphere and lower stratosphere as revealed by balloon sonde observations of water vapor, ozone, temperature and winds during the NASA TCSP and TC4 campaigns, J. Geophys. Res., 115, D00J19, doi:10.1029/2009JD013209, 2010.

Sioris, C. E., Boone, C. D., Bernath, P. F., Zou, J., McElroy, C. T., and McLinden, C. A.: Atmospheric Chemistry Experiment (ACE) observations of aerosol in the upper troposphere and lower stratosphere from the Kasatochi volcanic eruption, J. Geophys. Res., 115, D00L14, doi:10.1029/2009JD013469, 2010a.

Sioris, C., Zou, J., McElroy, C., McLinden, C., and Vömel, H.: High vertical resolution water vapour profiles in the upper troposphere and lower stratosphere retrieved from MAESTRO solar occultation spectra, Adv. Space Res., 46, 642-650, doi:10.1016/j.asr.2010.04.040, 2010b.

Sitnikov, N., Yushkov, V., Afchine, A., Korshunov, L., Astakhov, V., Ulanovskii, A., Kraemer, M., Mangold, A., Schiller, C., and Ravegnani, F.: The FLASH instrument for water vapor measurements on board the high-altitude airplane, Instrum. Exp. Tech., 50, 113-121, doi:10.1134/S0020441207010174, 2007.

Sofieva, V. F., Tamminen, J., Haario, H., Kyrölä, E., and Lehtinen, M.: Ozone profile smoothness as a priori information in the inversion of limb measurements, Ann. Geophys., 22, 3411-3420, doi:10.5194/angeo-22-3411-2004, 2004.

Solomon, S., Rosenlof, K. H., Portmann, R. W., Daniel, S. M. D., Sanford, T. J., and Plattner, G.-K.: Contributions of Stratospheric Water Vapor to Decadal Changes in the Rate of Global Warming, Science, 327, 1219, doi:10.1126/science.1182488, 2010.

Stenke, A. and Grewe, V.: Simulation of stratospheric water vapor trends: impact on stratospheric ozone chemistry, Atmos. Chem. Phys., 5, 1257-1272, doi:10.5194/acp-5-1257-2005, 2005.
Thomason, L. W., Burton, S. P., Iyer, N., Zawodny, J. M., and Anderson, J.: A revised water vapor product for the Stratospheric Aerosol and Gas (SAGE) II version 6.2 data set, J. Geophys. Res., 109, D06312, doi:10.1029/2003JD004465, 2004.

Thomason, L. W., Moore, J. R., Pitts, M. C., Zawodny, J. M., and Chiou, E. W.: An evaluation of the SAGE III version 4 aerosol extinction coefficient and water vapor data products, Atmos. Chem. Phys., 10, 2159-2173, doi:10.5194/acp-10-21592010, 2010.

Urban, J., Lautié, N., Murtagh, D., Eriksson, P., Kasai, Y., Loßow, S., Dupuy, E., de La Noë, J., Frisk, U., Olberg, M., Flochmoën, E. L., and Ricaud, P.: Global observations of middle atmospheric water vapour by the Odin satellite: An overview, Planet. Space Sci., 55, 1093-1102, doi:10.1016/j.pss.2006.11.021, 2007.

Vasic, V., Feist, D., Müller, S., and Kämpfer, N.: An airborne radiometer for stratospheric water vapor measurements at $183 \mathrm{GHz}$, IEEE T. Geosci. Remote, 43, 1563-1570, doi:10.1109/TGRS.2005.846860, 2005.

Vömel, H., Oltmans, S. J., Hofmann, D. J., Deshler, T., and Rosen, J. M.: The evolution of the dehydration in the Antarctic stratospheric vortex, J. Geophys. Res., 100, 13919-13926, 1995.

Vömel, H., Barnes, J. E., Forno, R. N., Fujiwara, M., Hasebe, F., Iwasaki, S., Kivi, R., Komala, N., Kyrö, E., Leblanc, T., Morel, B., Ogino, S.-Y., Read, W. G., Ryan, S. C., Saraspriya, S., Selkirk, H., Shiotani, M., Valverde Canossa, J., and Whiteman, D. N.: Validation of Aura Microwave Limb Sounder water vapor by balloonborne Cryogenic Frost point Hygrometer measurements, J. Geophys. Res., 112, D24S37, doi:10.1029/2007JD008698, 2007a.

Vömel, H., David, D. E., and Smith, K.: Accuracy of tropospheric and stratospheric water vapor measurements by the cryogenic frost point hygrometer: Instrumental details and observations, J. Geophys. Res., 112, D08305, doi:10.1029/2006JD007224, 2007b.

von Savigny, C., Ulasi, E. P., Eichmann, K.-U., Bovensmann, H., and Burrows, J. P.: Detection and mapping of polar stratospheric clouds using limb scattering observations, Atmos. Chem. Phys., 5, 3071-3079, doi:10.5194/acp-5-3071-2005, 2005.

Zöger, M., Afchine, A., Eicke, N., Gerhards, M.-T., Klein, E., McKenna, D. S., Mörschel, U., Schmidt, U., Tan, V., Tuitjer, F., Woyke, T., and Schiller, C.: A new family of balloon-borne and airborne Lyman photofragment fluorescence hygrometers, J. Geophys. Res., 104, 1807-1816, doi:10.1029/1998JD100025, 1999. 